Review Article

\title{
New Developments in the Classification, Pathogenesis, Risk Factors, Natural History, and Treatment of Branch Retinal Vein Occlusion
}

\author{
Jia Li, ${ }^{1,2}$ Yannis M. Paulus, ${ }^{2,3}$ Yuanlu Shuai, ${ }^{1}$ Wangyi Fang, ${ }^{1}$ Qinghuai Liu, ${ }^{1}$ and \\ Songtao Yuan ${ }^{1}$ \\ ${ }^{1}$ Department of Ophthalmology, The First Affliated Hospital of Nanjing Medical University, Nanjing, China \\ ${ }^{2}$ Department of Biomedical Engineering, University of Michigan, Ann Arbor, MI, USA \\ ${ }^{3}$ Department of Ophthalmology and Visual Sciences, University of Michigan, Ann Arbor, MI, USA \\ Correspondence should be addressed to Songtao Yuan; yuansongtao@vip.sina.com
}

Received 2 December 2016; Accepted 7 February 2017; Published 12 March 2017

Academic Editor: Paolo Lanzetta

Copyright () 2017 Jia Li et al. This is an open access article distributed under the Creative Commons Attribution License, which permits unrestricted use, distribution, and reproduction in any medium, provided the original work is properly cited.

\begin{abstract}
For years, branch retinal vein occlusion is still a controversial disease in many aspects. An increasing amount of data is available regarding classification, pathogenesis, risk factors, natural history, and therapy of branch retinal vein occlusion. Some of the conclusions may even change our impression of branch retinal vein occlusion. It will be beneficial for our doctors to get a deeper understanding of this disease and improve the treatment skills. The aims of this review is to collect the information above and report new ideas especially from the past a few years.
\end{abstract}

\section{Introduction}

Retinal vein occlusion (RVO) is the second most common type of retinal vascular disorder, after diabetic retinal disease, and one of the most common causes of the sudden painless unilateral loss of vision [1]. RVO can be divided into two main types: branch retinal vein occlusion (BRVO) and central retina vein occlusion (CRVO). The International Eye Disease Consortium reported the prevalence of retinal vein occlusion in the USA, Europe, Asia, and Australia which contained 68751 individuals aging from 31 to 101 years of 15 studies which shows that the prevalence of RVO was 5.20 per 1000 for any RVO, 4.42 per 1000 for BRVO, and 0.80 per 1000 for CRVO. It suggested that roughly 16 million people in the world suffer from this vascular disorder and BRVO is about 4 times more common [2]. Generally, BRVO has a better prognosis than CRVO. Without therapeutic intervention, visual acuity can still improve generally in eyes with BRVO but clinically significant improvement beyond 20/40 was uncommon [3].

\section{Classification}

BRVO can be divided into two different types according to Hayreh et al.: major BRVO, when one of the major branch retinal vein is occluded, and macular BRVO, when one of the macular venules is occluded, and these two types have different fundus changes $[4,5]$. Major BRVO comprises a nonischemic form and an ischemic form detectable in one third and two thirds of cases, respectively, and ocular neovascularization can only be found in ischemic major BRVO [6]. The typical arteriovenous crossing of major BRVO is situated along the course of a major venous branch. The location of the arteriovenous crossing with respect to the optic disc determines the extension of the area involved [7]. It is reported that $65 \%$ of BRVO occurred in the superior temporal quadrant. This is postulated to be due to increased arteriovenous crossing at this site or increased symptoms when the fovea becomes involved to affect the vision $[8,9]$. Macular BRVO represents a particular venous occlusion in which the obstruction is limited to a small vein draining a specific sector of the macula located between the superior 
and inferior temporal arcades [10]. Unlike ischemic major BRVO, macular BRVO does not develop retinal neovascularization (NV) because the ischemic area is too small to provide a sufficient stimulus for NV. A further group is hemi-vein occlusion, a distinct clinical entity presenting as occlusion of only one trunk of the central retinal vein in the area of the anterior part of the optic nerve. Hayreh et al. considered it as a separate type since its pathogenesis is quite similar to CRVO [10]. With the help of basic technology such as fundus photography, fundus fluorescein angiography (FFA), spectral domain optical coherence tomography (SD-OCT), visual field testing, and full-field electroretinogram (ff-ERG), BRVO and macular edema are usually easy to diagnose and classify [11-14]. In addition, new technology such as OCT angiography (OCTA) can measure vascular density and the foveal avascular zone. OCTA can also observe the superficial and deep capillary networks, nonflow areas, vascular dilation, and intraretinal edema, which can be helpful in diagnosis and follow-up [15-19].

\section{Pathogenesis}

The pathogenesis of RVO is multifactorial while BRVO may be due to a combination of three primary mechanisms: compression of the vein at the arteriovenous (A/V) crossing, degenerative changes of the vessel wall, and abnormal hematological factors. Arteriolar sclerosis due to various reasons such as hypertension or hyperlipidemia can result in more compression of the veins, which is the primary cause of BRVO. Zhao et al. evaluated the anatomic position of the crossing vessels in 106 eyes with BRVO and found the artery anterior to the vein at the obstructed site in $99 \%$ of affected eyes [20]. Also, the mechanical obstruction of the vein through the rigid artery in the A/V crossing may result in turbulent blood flow producing damage to the vein vascular endothelium and intima media and the sequence of events leading to occlusion of the vein, as reported by Christoffersen and Larsen [21]. Hyperviscosity due to high hematocrit has also been found to be associated with BRVO [22]. Viscosity is mainly dependent upon the hematocrit and plasma fibrinogen, and isovolumetric hemodilution does also positively impact it [23]. Another discussed hematological disorder in the pathogenesis of BRVO is the dysregulation of the thrombosis-fibrinolysis balance. The coagulation cascade including different blood factors results in the production of thrombin which converts circulating fibrinogen to fibrin. The coagulation sequence is held in check and inhibited by specific anticoagulants including protein $\mathrm{C}$, protein $\mathrm{S}$, and antithrombin. However, the results of published studies are inconsistent, and the role of coagulation factors in the development of RVO remains unclear [24]. It is well recognized that submacular hemorrhage from neovascular age-related macular degeneration (AMD) or retinal artery macroaneuryms (RAMs) often causes severe visual impairment $[25,26]$. Previous experimental studies have suggested several mechanisms by which subretinal hemorrhage damages the overlying photoreceptors, such as clot retraction, iron toxicity (hemosiderosis), induction of fibrosis, and blockage of nutrient diffusion from the choroidal circulation [27]. In BRVO, some of these mechanisms may be involved in the formation of foveal damage, although the mechanisms involved are not completely understood. An experiment carried out recently indicated that BRVO can cause acute endothelial cell apoptosis and increased permeability. Subsequently, the upstream vascular network remains destabilized, characterized by pericyte dropout, abnormally high endothelial cell turnover, and sensitivity to hypoxia. These early changes might pave the way for capillary loss and subsequent chronic ischemia and edema that characterize the late stage disease [28].

\section{Cystoid Macular Edema}

Cystoid macular edema (CME) is the main cause of impaired vision due to $\mathrm{BRVO}$ and occurs in $30 \%$ of BRVO eyes [29]. It was hypothesized to be caused by fluid flux from vessels to tissue according to Starling's law, which is based on the breakdown of the blood-retinal barrier as a result of damage to the tight junctions of capillary endothelial cells, vitreoretinal adhesion, and secretion into the vitreous of vasopermeability factors produced in the retina [30-33]. Noma et al. suggested that in patients with BRVO, vascular occlusion induces the expression of vascular endothelial growth factor (VEGF) which is promoted by hypoxia and retinal nonperfusion and interleukin-6 (IL-6), resulting in blood-retinal barrier (BRB) breakdown and increased vascular permeability which results in macular edema [34-36]. Moreover, aqueous levels of other growth factors such as placental growth factor (PIGF), platelet-derived growth factor (PDGF)-AA, and various inflammatory factors including soluble intercellular adhesion molecule (sICAM-1), monocyte chemoattractant protein (MCP-1), interleukin (IL)-6, IL-8, IL-12, and IL-13 as well as soluble vascular endothelial growth factor receptor (sVEGFR)-1 and sVEGFR-2 were found to be significantly higher and correlated with CME [36-38]. The inflammatory factors may induce an increase of vascular permeability and disrupt the blood-aqueous barrier, but further studies are needed to elucidate the exact pathophysiology [39]. Recently, a study reported that aqueous angiopoietin-like 4 (ANGPTL4) level in patients with ME due to BRVO is also significantly higher [40]. The ANGPLTL4 mediates the development of vascular permeability and angiogenesis in hypoxic conditions, is overexpressed in general ischemic retinopathy, and promotes the development of CME [41, 42]. If marked hypoxia persists, irreversible structural changes in the macular occur, and the disturbed visual acuity (VA) is almost always lasting. Moreover, it is recently reported that aqueous erythropoietin (EPO) level is also higher than normal in BRVO patients, especially during the acute period [43]. The EPO was found to be associated with retinal ischemia and provides neuroprotective effects against ischemia-reperfusion injury and light-induced retinal degeneration in animal models $[44,45]$. It was discovered that there exists a strong correlation between EPO and VEGF. Higher concentrations of vitreous EPO 
in BRVO are exclusively caused by the retinal hypoxia and are related to CME [46].

\section{Risk Factors}

BRVO has many known ophthalmic and systemic risk factors considering its complicated pathogenesis. It is widely known that advancing age is an important risk factor for BRVO since the main pathogenic mechanism of BRVO is arterial stiffness that causes venous compression in the common adventitial sheath [2, 47]. Systemic vascular diseases like hypertension (HTN), hyperlipidemia (HLD), and peripheral arterial disease (PAD) and metabolic diseases like diabetes mellitus (DM) are all connected with BRVO. A meta-analysis showed that, in BRVO, the odds ratio for HTN, HLD, and DM is $3.0,2.3$, and 1.1 , respectively [48]. A study in 2014 enrolled 492488 patients older than 55 years demonstrated that HTN seems to be the main driver of the increased risk for incident BRVO and those with more severe HTN were at even greater risk. Also, they discovered that persons with "uncomplicated" DM had no difference in the risk of being diagnosed with BRVO, while those with end organ damage from DM had a 36\% increased risk, but no association between dyslipidemia and BRVO was found. However, the presence of dyslipidemia actually attenuated some of the increased risk of BRVO among persons who had multiple components of the metabolic syndrome [49]. Also Lam et al. reported that risk factors for developing BRVO younger than 50 years were very similar to those in older people (HTN, HLD, and high body mass index (BMI)); therefore, these two articles together can make a whole story [50]. It is not completely clear what role thrombophilia plays in the BRVO pathogenesis. Blood abnormalities play a controversial role in the pathogenesis of BRVO, and erythrocyte volume, level of fibrinogen, and hematocrit appear to be important [22-24]. Three recent meta-analyses of RVO and thrombophilic factors demonstrated that only hyperhomocysteinemia and anticardiolipin antibodies play a role in the pathogenesis of RVO [24, 29, 51]. Additional studies also reported other less common risk factors such as obstructive sleep apnea (OSA), inadvertent retrobulbar needle perforation, axial length and vitreous chamber depth, liver or renal diseases, and even posterior vitreous adhesion [52-57]. Moreover, BRVO may also be easier to find in people with gene defects, like adiponectin $+276 \mathrm{G} / \mathrm{T}$ and AGTR1 A1166C single-nucleotide polymorphism, which are related to arterial stiffness [58]. Blacks were also found to be at increased risk of developing incident ophthalmic venous occlusive disease, even after controlling for HTN, other components of the metabolic syndrome, and sociodemographic factors [49]. These results support earlier work by the International Eye Disease Consortium, which showed a greater prevalence of BRVO among blacks compared with whites [2]. There are many hypotheses as to why blacks may be at greater risk for end organ vascular damage, ranging from reduced access to high-quality health care, to racism potentially leading to chronic stress, to living in neighborhoods with higher levels of pollution, and to living in unsafe neighborhoods impacting their ability to exercise, which can all lead to an increased burden of vascular disease [2].

\section{Natural History}

BRVO has a relatively better vision outcome compared to CRVO, with $50 \%$ to $60 \%$ of eyes recovering vision to $20 / 40$ or better without treatment and with $25 \%$ which may develop retinal neovascularization [6]. The natural course of BRVO is determined by the site and degree of occlusion, the integrity of arterial perfusion to the affected sector, and the efficiency of the developing collateral circulation [59]. According to Hayreh et al., the median time to macular edema resolution was 21 months in those with major BRVO and 18 months in those with macular BRVO. Overall, for eyes with initial VA of 20/60 or better, VA improved or remained stable in $75 \%$ for major BRVO and $86 \%$ for macular BRVO. In those with initial VA of $20 / 70$ or worse, VA improved in $69 \%$ for major BRVO and in $53 \%$ for macular BRVO, with median final VA of 20/60 for both BRVO types [60]. On follow-up, in temporal main BRVO, visual field defect improved or remained stable in $68 \%$ of eyes with minimal to mild initial defect and improved in 52\% of eyes with moderate to severe initial defect. In macular BRVO, visual field defect remained stable or improved in $85 \%$ of eyes with minimal to mild initial defect [9]. A meta-analysis reported that $10 \%$ of the patients can observe the development of fellow eye involvement [3]. Although a majority of BRVO eyes had variable amounts of VA improvement without treatment, there was a lack of improvement in some eyes, which may be due to the same factors as those seen in ischemic central retinal vein occlusion: ischemic damage to macular retinal ganglion cells, pigmentary degeneration, and development of an epiretinal membrane from prolonged macular edema [5, 61-65].

\section{Treatment}

The treatment of BRVO is comprised of three main stages: identification and treatment of modifiable risk factors, specific treatment of the vascular occlusion, and treatment of BRVO complications such as macular edema, retinal neovascularization, vitreous hemorrhage, and traction retinal detachment so as to improve visual acuity and metamorphopsia [66]. The main purpose of all treatments is the resolution of the macular edema (the leading cause of impaired visual acuity and metamorphopsia) before the foveal photoreceptor layer is damaged $[67,68]$. The management of macular edema secondary to branch retinal vein occlusion has greatly improved in recent times with the introduction of a therapy based on intravitreal injection of antivascular endothelial growth factor (VEGF) molecules and steroids [69]. Patient outcomes even with identical treatments can be vastly different due to disease, and patient heterogeneity prognostic factors for BRVO include patient age [70], baseline visual acuity and retinal thickness $[51,71,72]$, early response to treatment [70], duration of macular edema $[73,74]$, posterior vitreous detachment [75], OCT characteristic [76-78], cytokine level [34, 79], central retinal sensitivity [80], leaking capillaries and microaneurysms in 
the perifoveal capillary network $[60,81,82]$, retinal pigment epithelium (RPE) integrity [83, 84], serious retinal detachment [85], and subretinal hemorrhage [86]. Some of these prognostic factors are still controversial. Basically, patients with a younger age, milder symptom (such as nonischemic BRVO), shorter duration of CME, and better response to early treatment tend to have a better outcome. A recent survey reported that retina specialists treating CME secondary to RVO recommend different treatments for patients than they would choose for themselves. This suggests that cognitive biases exist and one should take this into consideration when making treatment recommendations for their patients [87].

7.1. Anti-VEGF. Inhibitors of vascular endothelial growth factor (VEGF) have revolutionized the treatment of CME associated with BRVO, a condition that is sensitive to VEGF. Several lines of evidence suggest that VEGF is a major mediator for $\mathrm{CME}$ in $\mathrm{BRVO}[33,34]$ and have demonstrated the resolution of $\mathrm{CME}$ and improvement of vision in response to pharmacologic VEGF inhibition [88]. The most commonly used anti-VEGF drugs at this time are bevacizumab (Avastin), aflibercept (Eylea), and ranibizumab (Lucentis). Selected clinical trials are collected in Table 1 [89-99].

Bevacizumab is a recombinant humanized and chimeric IgG1 type monoclonal antibody, directed against all the isoforms of the VEGF peptide to block angiogenesis. Many studies have reported that visual acuity and macular edema improved significantly after intravitreal bevacizumab (IVB) treatment and also cause a significant decrease in sVEGFR-1, VEGF, PDGF-AA, MCP-1, and IL-8 [38, 89]. A recent study showed that after IVB treatment, there is an increase of retinal venous outflow that may possibly influence the resolution of macular edema [100]. Compared with intravitreal triamcinolone acetonide, intravitreal bevacizumab can achieve better long-term VA outcomes with much lower rate of adverse events (e.g., cataract and glaucoma), despite the fact that triamcinolone acetonide may achieve equal visual acuity and morphology improvement for the first few months right after treatment [101, 102]. Also, IVB can result in better outcome in the recurrent CME, while subthreshold grid laser was completely ineffective [103]. However, CME due to BRVO has a relatively high rate of recurrence. Only 30\%$34 \%$ of IVB-effective eyes can achieve persistent resolution of CME, whereas most need additional treatments to optimize visual acuity [104-106]. The duration from symptom onset to initial IVB could affect the CME recurrence rate but not the efficacy rate after a single IVB injection [104].

Aflibercept is a fusion protein that combines key domains from human VEGF receptors VEGFRs-1 and VEGFRs-2 with the constant region $\mathrm{Fc}$ of human immunoglobulin $\mathrm{G}$ and binds multiple VEGF-A isoforms. The VIBRANT study $(n=183)$ included patients from North America and Japan and showed that $52.7 \%$ of the affected eyes had a visual improvement of more than 15 Early Treatment of Diabetic Retinopathy Study (ETDRS) letters with a mean improvement of 17 ETDRS letters. It also recommended a treatment mode of intravitreal aflibercept (IVA) every 8 weeks after a 24-week period of IVA every 4 weeks to obtain an optimal outcome at 52 weeks [91].

Ranibizumab is a Fab fragment that specifically binds all isoforms of vascular endothelial growth factor A. Both the BRAVO study ( $n=397)$ and the BRIGHTER study $(n=455)$ demonstrated with ranibizumab a statistically significant superior improvement in best-corrected visual acuity (BCVA) compared with laser alone in patients with BRVO. No ocular side adverse effects (SAEs) were reported in this group [90, 107]. Although many studies claimed that intravitreal ranibizumab (IVR) can improve retinal nonperfusion, the effect was usually limited [108]. As discussed above, patients treated with IVR often have CME recurrence and needed frequent additional injections to cause complete CME resolution [95]. It is reported that four years after initial treatment, half of the patients still require treatment, but most of the outcomes were excellent [97]. In the natural course of acute BRVO, intraretinal hemorrhage and CME are absorbed gradually. However, IVR accelerates the speed of absorption of intraretinal hemorrhage and is associated with a rapid reduction of $\mathrm{CME}$. Because there has been no evidence that anti-VEGF drugs modify the function of macrophages and microglia which can phagocytose debris and red blood cells, one can only postulate that ranibizumab does not facilitate the absorption of intraretinal hemorrhage directly but rather suppresses new bleeding and thus seemingly accelerates absorption [109].

Recently, conbercept (KH902), a recombinant and soluble VEGF receptor fused to the Fc portion of human IgG1 with $100 \%$ human protein sequence, has been developed. Because the addition of the binding domain of VEGFR-2, conbercept can bind to all isoforms of VEGF-A, VEGF-B, and placental growth factor, so it has a very strong effect on antiangiogenesis [110, 111]. KH902 has been widely used in China to treat ocular neovascular diseases which include wet AMD and diabetic retinopathy with great success and has been approved by FDA for stage III clinical trial [112-114]. This kind of VEGF inhibitor is much cheaper, while theoretically more efficient. However, conbercept has not been proven to treat CME secondary to BRVO or CRVO yet, but the phase III clinical trial has started in China recently.

Different anti-VEGF drugs may have varying treatment patterns and dosages. The recommended dosage is $0.5 \mathrm{mg}$, $2.0 \mathrm{mg}$, and $1.25 \mathrm{mg}$ for ranibizumab, aflibercept, and bevacizumab, respectively $[115,116]$. Some specialists preferred a monthly injection, while others employ a treat and extend (TREX) or an as needed (pro re nata) regimen [93, 106, 117-120]. A recent study reported that BRVO patients can receive good VA and central macular thickness (CMT) outcomes with a lower frequency of intravitreal ranibizumab. The total mean number of injections over 12 months follow-up was 2.1 for BRVO and 3.4 for CRVO [119]. In addition, frequent injection of VEGF inhibitors may also increase the risk of SAEs and could possibly lead to retinal atrophy secondary to obstruction of neuroprotective cytokines and regression of normal vasculature [121, 122]. There is still limited data on the comparative effectiveness of different anti-VEGF drugs at this time because the design of the 


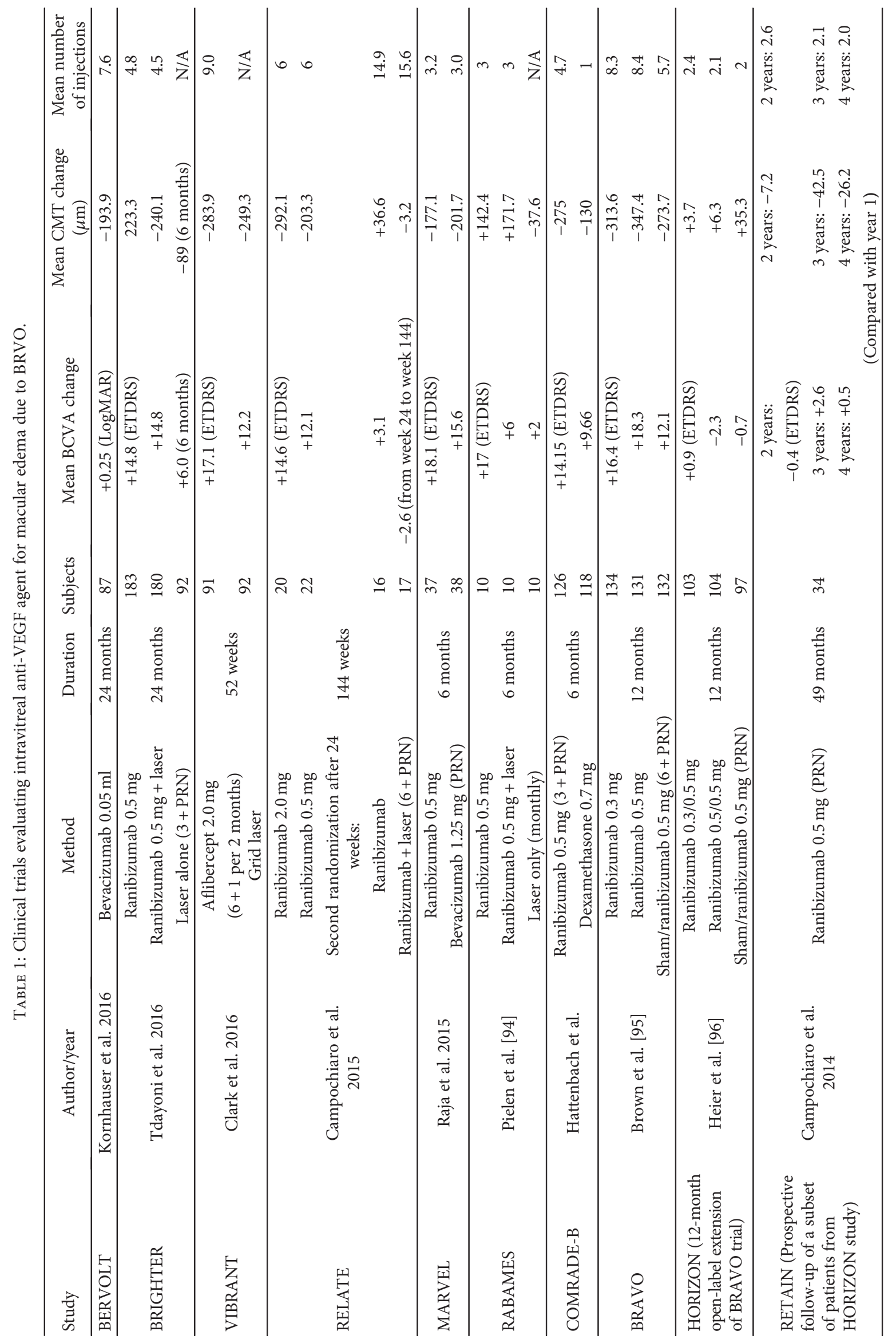




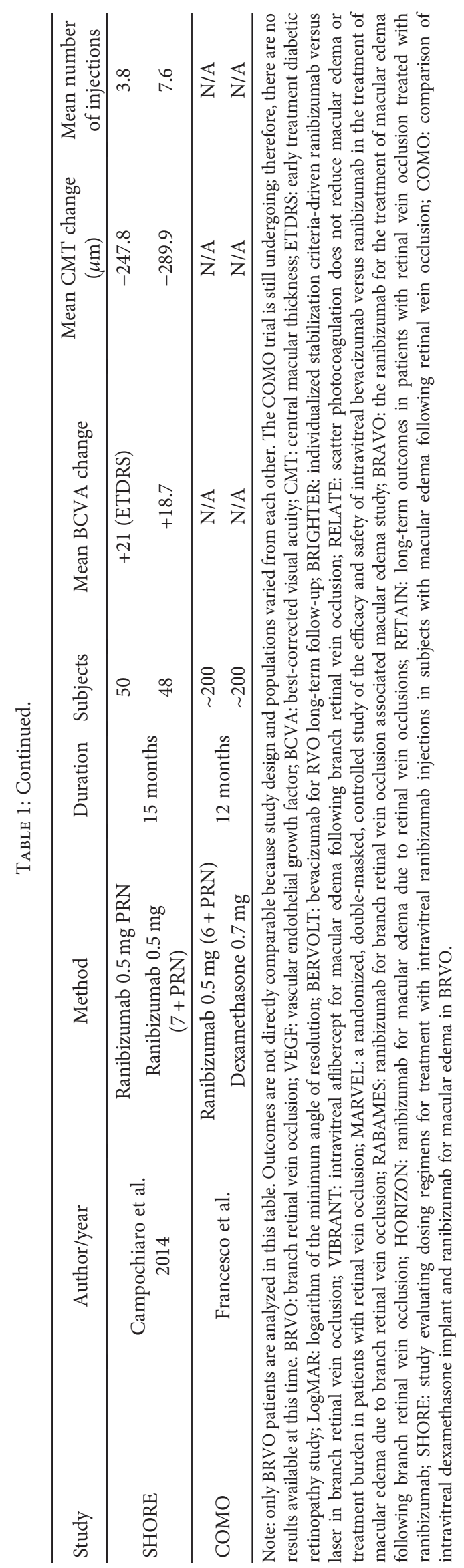


studies varies from each other. Interestingly, bevacizumab is the preferred treatment option by $61 \%$ of the US retina specialists followed by aflibercept (17\%) and ranibizumab (17\%), as revealed by the American Society of Retina Specialists (ASRS) 2015 Membership Preferences and Trends Survey. This indicates that economical considerations contribute a major part toward decision making in clinical practice [123].

7.2. Corticosteroids. Intravitreal corticosteroids is another option, particularly in situations where the cost of treatment and the monthly treatment burden of anti-VEGF therapy is too difficult for patients [124]. The most commonly used steroid drug is triamcinolone acetonide (TA), which is reported to have similar or even better shortterm outcomes especially in nonischemic BRVO compared with anti-anti-VEGF drugs. Research has demonstrated that both 3-month intravitreal injections of an antiVEGF agent bevacizumab and two IVTA injections 2 months apart could be effective in respect to both visual and anatomical outcomes [125]. TA has much lower prices but has a higher rate of adverse events like increased intraocular pressure (IOP), cataract progression, and sterile pseudoendophthalmitis $[101,124,126-130]$. The SCORE study $(n=411)$ showed that the outcome of IVTA $1 \mathrm{mg}$ groups is similar to IVTA $4 \mathrm{mg}$ groups and can lower the rate of adverse events [131]. TA has numerous mechanisms of action, including anti-inflammatory effects, antiangiogenic properties and inhibition of VEGF, and other inflammatory cytokine expressions, such as IL-6, ICAM-1, and MCP-1 $[132,133]$. Ozkiris et al. evaluated the effect of TA injection on persistent CME in BRVO that failed to respond to previous laser photocoagulation. During a mean follow-up time of 6.2 months, best-corrected VA improved significantly from 1.01 at baseline to 0.55 (LogMAR) at one month after the injection. VA after 3 months was 0.56 , and at the end of follow-up was 0.62 [134]. Moreover, intravitreal TA (IVTA) may also improve macular sensitivity and morphology in patients with either ischemic or nonischemic BRVO [135].

Response to TA differs among eyes with edema, some only needing one injection, while most patients still need treatment for multiple times $[136,137]$. Predictive factors for successful IVTA treatment were younger age, shorter duration of $\mathrm{CME}$, initial onset $\mathrm{CME}$, concurrent serous retinal detachment, few concomitant systemic diseases, intact foveal capillary ring, eyes with cystoid spaces in the outer plexiform layer, and nonischemic BRVO [134, 138].

Posterior subtenon triamcinolone acetonide (STA) has the advantage of easy injection and decreased risk of intraocular complications such as IOP elevation and cataract progression compared with IVTA, but the efficacy of STA is thought to be slightly less than that of IVTA $[136,139,140]$.

Another steroid therapy is the dexamethasone intravitreal implant (Ozurdex), which provides continuous steroid delivery over a more sustained period, permitting longer duration of action and has been proved by previous studies [141-145]. The 12-month result of GENEVA trial ( $n=1196)$ showed that eyes receiving DEX implant 0.7 or $0.35 \mathrm{mg}$ achieved a 15-letter improvement in BCVA significantly faster than the eyes receiving sham treatment. At day 180 , the cumulative response rate was $41 \%$ in the DEX implant $0.7 \mathrm{mg}$ group, $40 \%$ in the DEX implant $0.35 \mathrm{mg}$ group, and $23 \%$ in the sham group. There was no significant difference in efficacy and safety between $0.7 \mathrm{mg}$ group and $0.35 \mathrm{mg}$ group. However, the overall incidence of ocular adverse events was significantly higher in the DEX implant $0.7 \mathrm{mg}$ group (62.9\%) and DEX implant $0.35 \mathrm{mg}$ group $(61.9 \%)$ than in the sham group $(42.8 \% ; P<0.001)$. The only adverse events that occurred significantly more frequently were eye pain $(P=0.023)$, ocular hypertension $(P \leq 0.002)$, and anterior chamber cells $(P \leq 0.031)$. Most of the participants met the visual acuity or retinal thickness criteria for retreatment at day 180 which showed as safe and well tolerated over 12 months. The safety and efficacy profile after a second treatment with DEX implant was generally similar to that seen after the first treatment, and patients who had delayed treatment never matched the improvement of those treated earlier in the disease process $[146,147]$. The ORVO study $(n=17)$ also demonstrated that Ozurdex can reduce several propermeability proteins such as persephin, pentraxin 3 , hepatocyte growth factor, endocrine gland VEGF, insulin-like growth factor binding proteins, and proinflammatory cytokines like MCP-1 and IL17-E [148, 149]. Also, the SHASTA study $(n=289)$ demonstrated that the visual acuity and central retinal thickness significantly improved both after initial or retreatment. $32.6 \%$ of patients were observed with elevated IOP whereas only $1.7 \%$ needed glaucoma surgery [150]. However, the OMAR study recently found no difference between Ozurdex and TA regarding anatomical or functional outcomes or the incidence of side effects, although the number of intravitreal injections was reduced by using Ozurdex [151]. Selected clinical trials are summarized in Table $2[131,146,148,150,152]$

7.3. Laser Photocoagulation. Venous occlusion is merely the initiating event that causes retinal ischemia and high levels of VEGF. The high levels of VEGF cause additional capillary closure and worsening ischemia, resulting in a positive feedback loop and disease progression over time in some patients $[153,154]$. In 1986, the Branch Vein Occlusion Study (BRVOS) reported the efficacy of grid-pattern laser photocoagulation for treating macular edema due to BRVO and recommended this method as the standard treatment for BRVO [155]. The efficacy of grid-pattern laser photocoagulation is thought to result from changes in the biochemical processes within the retinal pigment epithelium (RPE) or hypoxia in the neural retina [156, 157]. The pigment epitheliumderived factor, which can inhibit retinal and choroidal neovascularization by inducing apoptosis in activated vascular endothelial cells, is reported to be upregulated in photocoagulated human retinal pigment epithelial cells [157, 158]. VEGF expression is found to increase a few days after laser treatment and then start to decrease [159]. Moreover, direct photocoagulation to leaking vessels and microaneurysms is found to be beneficial for treating chronic macular edema associated with chronic BRVO of longer than 12 months duration [160]. 


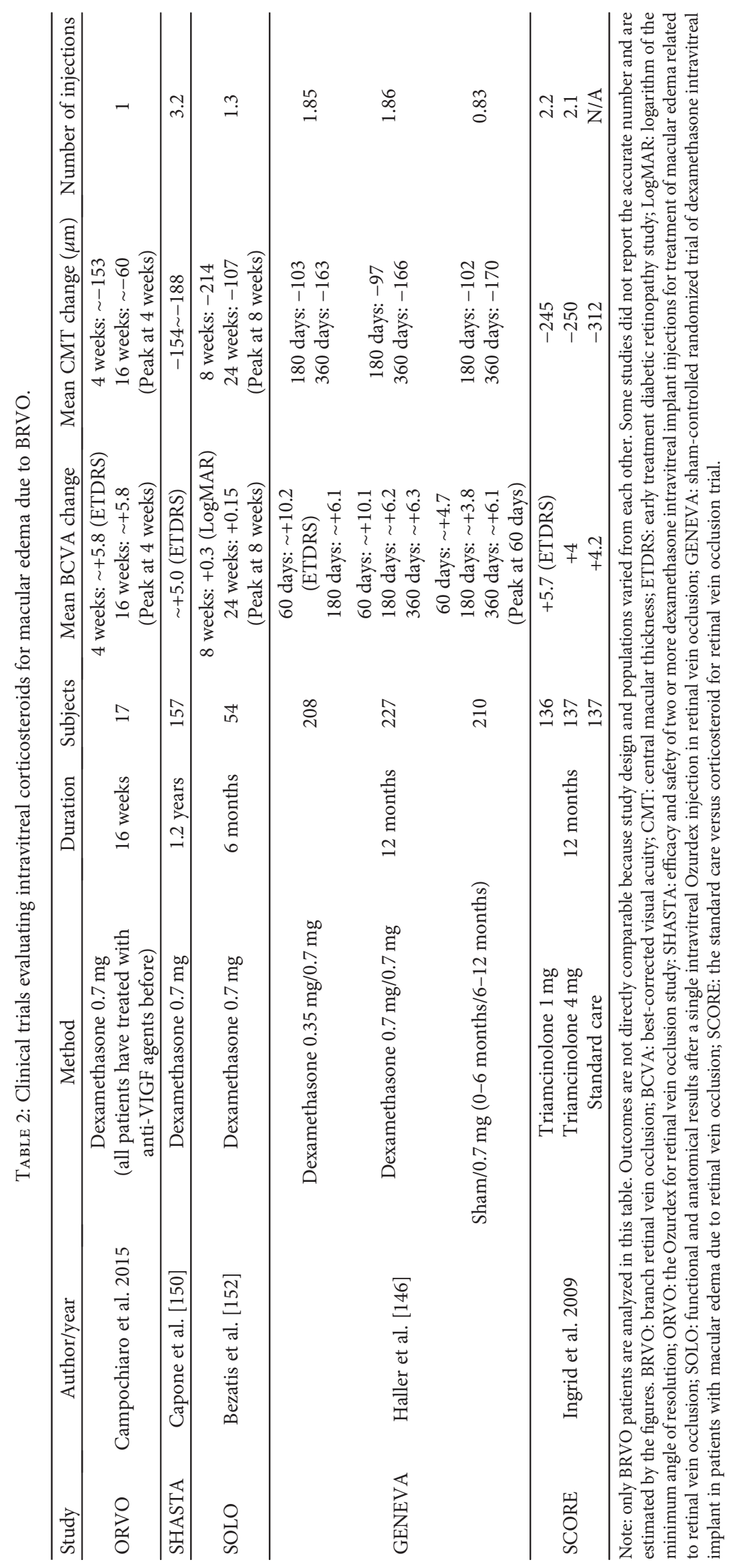


Peripheral scatter photocoagulation can reduce retinal ischemia. Theoretically, it may provide a way to interrupt the positive feedback loop in patients with BRVO and reduce the need for injections of a VEGF antagonist. However, the RELATE trial found that peripheral scatter laser did not benefit in BCVA, resolution of edema, or number of ranibizumab injections [92]. The group has also come up with three speculations: (1) the untreated area is hypoxic and can still release enough VEGF to cause persistent or recurrent edema; (2) chronic hypoxia, high levels of VEGF, and recurrent leakage can lead to structural changes in retina vessels; and (3) the reduction of VEGF is countered by inflammation and production of propermeability factors induced by photocoagulation [92].

Conventional laser therapy can result in enlarged retinal scars, subretinal fibrosis, choroidal neovascularization, and reduced macular sensitivity [161-164]. Subthreshold micropulse diode laser photocoagulation (SMDLP) is a less invasive treatment than conventional focal or grid laser therapy designed to produce lesions on the retinal pigment epithelium (RPE) while having minimal effect on the neurosensory retina. Small studies have demonstrated good clinical outcomes with micropulse laser, for initial visual acuity better or worse than 20/40, although larger studies are necessary [165-168]. However, in specific subsets of patients such as recurrent CME after conventional laser treatment, antiVEGF treatment is still the preferred treatment rather than SMDLP [102].

Efficacy of conventional laser treatment is always limited, compared with anti-VEGF therapy and corticosteroids $[90,91,169]$. As a result, anti-VEGF therapy has taken the place of conventional laser treatment as first-line treatment for CME, and many studies put laser treatment as a rescue therapy or in combination therapy $[97,101,170]$.

Another rarely used technique is laser-induced arteriolar construction (ACo), first described by L'Esperance in 1975. ACo is based on the sacrificial constriction of the afferent arteriole in the occluded BRVO region. Results using ACo have reported significantly improved BCVA in BRVO patients [171, 172]. Constriction of the afferent artery in the BRVO region accelerated the restoration of potassium channels and IL-6. These alterations may contribute to faster resorption of retinal edema and may decrease the level of inflammation [173]. However, further prospective randomized studies are needed.

7.4. Surgery. Considering the mechanism of vein occlusion, arteriovenous sheathotomy (AVS) would appear to be a reasonable treatment for BRVO. In 1988, Osterloh and Charles were the first to report a surgical procedure involving dissection of the common adventitial sheath at the level of the arteriovenous blockage site for decompressing the arteriovenous crossing [174]. The AVS not only released the pressure at $\mathrm{A} / \mathrm{V}$ crossing but also decreased the IL-6 expression [175]. The efficacy of this method, however, was controversial [176-179]. A recent clinical trial using a modified control group demonstrated that eyes which went through AVS had significantly better vision acuity and central macular thickness than those in the control group, which is thought to be more convincing than the previous studies. But they also conducted internal limiting membrane peeling during the surgery, which may have some impact on the result [180]. Another study found that the pars plana vitrectomy (PPV) combined with AVS is safe and effective and can cause the disappearance of collateral vessels at the blockage site, which is an important clinical marker for intravascular reperfusion [181].

In 2004, Charbonnel et al. reported that eyes with an initial posterior vitreous detachment (PVD) had less improvement of visual acuity than those without a PVD after AVS and suggested that the surgical detachment of posterior hyaloid could be as important (or more) as the sheathotomy itself [182]. This theory was replicated by another study which showed that there was no significant difference in the improvement of macular function between the vitrectomy with or without arteriovenous adventitial sheathotomy group [183]. Similarly, vitrectomy with internal limiting membrane (ILM) peeling has been suggested as a potential treatment because it is generally believed that vitreous traction on the macula leads to fluid accumulation in the retina. Removal of posterior hyaloid may improve oxygenation of the retina [184]. However, Arai et al. found no difference in the results of vitrectomy with internal limiting membrane (ILM) peeling and that without ILM peeling, emphasizing the importance of vitrectomy [185]. Vitrectomy can help remove the vitreomacular traction and thus improve cytokines that affect vascular permeability. It was also reported that the oxygen tension is higher after vitrectomy, resulting in capillary shrinkage, reduced blood vessel leakage, and absorption of macular edema [186]. Posterior vitreous adhesion is thus considered an independent risk factor and also a prognostic factor for BRVO, and vitrectomy may be the most valuable part of the surgery $[56,75]$.

Another surgical method is the retinal bypass surgery, the feasibility has been proved recently this year, but the efficacy still needs further study [187]. Although surgery may not be the first choice to most physicians, it is still an option when other treatment is not effective in some patients [188].

7.5. Medical Treatment. It is reported that an increase in small platelet aggregates may play a component in BRVO pathogenesis. Beraprost and ticlopidine inhibit small aggregate formation in BRVO patients and may represent effective antiplatelet treatments [189]. Houtsmuller et al. compared the effect of ticlopidine, an antiplatelet aggregative factor, versus placebo in 54 patients with BRVO and found a significant improvement in visual acuity in $69 \%$ BRVO patients of ticlopidine group versus $52 \%$ of the placebo group in a six-month follow-up [190]. Glacet Bernard et al. examined the efficacy of troxerutin, an antierythrocyte and antiplatelet aggregative drug, versus placebo in 26 patients with BRVO less than five months from symptom onset. In a two-year follow-up, there was a significant improvement in visual acuity, as well as in macular edema, in patients treated with troxerutin compared to those treated with placebo [191].

Tissue plasminogen activator (t-PA) intravitreally or directly into the retinal vein is another treatment option 
for BRVO. Small studies have demonstrated the safety and an improvement in visual acuity and foveal thickness with t-PA treatment [192-196].

Low-molecular-weight heparins (LMWHs) have been also used and are considered to be effective for the treatment of BRVO, supporting the hypothesis that BRVO is a venous thrombotic disorder. No increased risk of vitreous hemorrhages was observed during treatment with LMWH while there was an improvement in the visual acuity [197, 198].

NSAIDs have been used to reduce the occurrence and severity of macular edema after cataract surgery, without causing elevation of intraocular pressure (IOP). A recent study with 15 BRVO patients suggested that intravitreal diclofenac is also safe and effective in improving BCVA and decreasing CMT in patients with BRVO and ME with the mean visual acuity improvement from $0.115 \pm 0.03$ preoperatively to $0.356 \pm 0.29$ ( $\log M A R)$. The mean preoperative CMT decreased from $453.2 \mu \mathrm{m} \pm 55.3 \mu \mathrm{m}$ to $340.47 \mu \mathrm{m} \pm 101 \mu \mathrm{m}$ at 3 months [199].

These medical therapies have demonstrated possible efficacy in treating CME due to BRVO in small studies. However, due to a small number of patients, further studies are necessary to ensure effectiveness.

7.6. Isovolemic Hemodilution. BRVO has been found to be associated with hyperviscosity due to higher hematocrit and plasma viscosity $[22,200]$. Viscosity is mainly dependent upon the hematocrit and plasma fibrinogen. Higher blood viscosity is less important when blood flow rate is rapid. In conditions of low flow, as is likely in a vein predisposed to occlusion, the effect of viscosity becomes increasingly significant as a result of increased red cell aggregation. The enhanced aggregation at slow flow rates further decreases flow leading to a vicious cycle of increased viscosity promoting increased aggregation which further increases viscosity, resulting in a state of "rheological obstruction" [22, 201]. Additionally, the occlusion-induced hypoxia will increase blood viscosity as acidosis increases red cell aggregability and reduces red cell deformability $[202,203]$. And both these red cell anomalies may pre-exist in patients with BRVO [204]. A study investigated 34 BRVO patients and obtained positive effect on the visual outcome with a target hematocrit of $35 \%$. The visual acuity in the isovolemic hemodilution therapy group improved by $0.20 \mathrm{Log}-$ MAR units at 6 weeks and 0.43 -LogMAR units at 1 year, which was statistically significant compared with that in the control group [23]. However, the systemic complications of this method make it less desirable than other available therapies.

7.7. Combined Therapy. There are many forms of treatment to BRVO as described above. Therefore, some investigators came up with the idea that combination therapy with two or more agents may be beneficial to get better outcomes with lowered dose, rate of adverse events, and less frequent treatment. Repeated intravitreal injections of an anti-VEGF can cause adverse effects such as ocular pain, ischemic retinopathy, and endophthalmitis, in addition to the high cost of
anti-VEGF drugs like ranibizumab [205, 206]. It is reported that bevacizumab combined with macular grid and scatter laser photocoagulation targeted retinal photocoagulation (TRP) of peripheral nonperfused areas (NPAs) could significantly improve vision, reduce macular edema, and prevent the recurrence of CME better than bevacizumab alone [207, 208]. Also, a lower number of reinjections were observed in the combined treatment [209]. The application of topical bromfenac, a nonsteroidal anti-inflammatory drug during IVB therapy in eyes with ME secondary to BRVO, was found to have the advantage of reducing the number of injections although it did not affect the visual prognosis [210]. Other combination therapies that have been investigated include corticosteroids with laser, anti-VEGF agents with corticosteroids, anti-VEGF agents with laser, and AVS or PPV with corticosteroids, to name a few [211-219]. Although most of these studies reported excellent outcomes, it is difficult to compare between studies to discern which is the best combination.

\section{Conclusion}

Branch retinal vein occlusion is a very common retinal disease. Numerous studies have been carried out evaluating every aspect of this ocular vascular dysfunction. The most commonly used treatments at this time are anti-VEGF drugs and corticosteroids, since they bring about significant improvement in VA and CMT with relatively fewer complications. Even if one treatment is not effective in particular patients, there are numerous treatments and combination therapies that can be considered. Novel treatments have revolutionized our care of patients with retinal vein occlusions. Further studies into the pathophysiology, risk factors, and treatment of retinal vein occlusions remain ongoing, and we continue to improve our treatment of patients with this difficult disease through personalized medicine and development of new methods and treatments.

\section{Conflicts of Interest}

The authors declare that there is no conflict of interest regarding the publication of this paper.

\section{References}

[1] S. Cugati, J. J. Wang, E. Rochtchina, and P. Mitchell, "Ten-year incidence of retinal vein occlusion in an older population: the blue mountains eye study," Archives of Ophthalmology, vol. 124, no. 5, pp. 726-732, 2006.

[2] S. Rogers, R. L. McIntosh, N. Cheung et al., "The prevalence of retinal vein occlusion: pooled data from population studies from the United States, Europe, Asia, and Australia," Ophthalmology, vol. 117, no. 2, pp. 313-9.e1, 2010.

[3] S. L. Rogers, R. L. McIntosh, L. Lim et al., "Natural history of branch retinal vein occlusion: an evidence-based systematic review," Ophthalmology, vol. 117, no. 6, pp. 1094-101.e5, 2010.

[4] S. S. Hayreh, "Retinal vein occlusion," Indian Journal of Ophthalmology, vol. 42, no. 3, pp. 109-132, 1994. 
[5] S. S. Hayreh and M. B. Zimmerman, "Fundus changes in central retinal vein occlusion," Retina, vol. 35, no. 1, pp. 29-42, 2015.

[6] S. S. R. P. Hayreh, P. Podhajsky, P. Montague, and R. F. Woolson, "Ocular neovascularization with retinal vascular occlusion-III. Incidence of ocular neovascularization with retinal vein occlusion," Ophthalmology, vol. 90, no. 5, pp. 488-506, 1983.

[7] R. M. T. B. Feist, M. J. Shapiro, and M. Farber, "Branch retinal vein occlusion and quadrantic variation in arteriovenous crossings," American Journal of Ophthalmology, vol. 113, no. 6, pp. 664-668, 1992.

[8] R. Thapa, G. Paudyal, and P. S. Bernstein, "Demographic characteristics, patterns and risk factors for retinal vein occlusion in Nepal: a hospital-based case-control study," Clinical \& Experimental Ophthalmology, vol. 38, no. 6, pp. 583-590, 2010.

[9] W. A. Samara, A. Shahlaee, J. Sridhar, M. A. Khan, A. C. Ho, and J. Hsu, "Quantitative Optical Coherence Tomography Angiography Features and Visual Function in Eyes With Branch Retinal Vein Occlusion," American Journal of Ophthalmology, vol. 166, pp. 76-83, 2016.

[10] S. S. Z. B. Hayreh and P. Podhajsky, "Incidence of various types of retinal vein occlusion and their recurrence and demographic characteristics," American Journal of Ophthalmology, vol. 117, no. 4, pp. 429-441, 1990.

[11] A. Szigeti, M. Schneider, M. Ecsedy, Z. Z. Nagy, and Z. Recsan, "Optic disc morphology in unilateral branch retinal vein occlusion using spectral domain optical coherence tomography," BMC Ophthalmology, vol. 15, no. 1, 178 pages, 2015.

[12] M. R. Munk, G. Matt, M. Baratsits et al., "Multimodal imaging of cotton wool spots in branch retinal vein occlusion," Ophthalmic Research, vol. 54, no. 1, pp. 48-56, 2015.

[13] H. Noma, T. Mimura, M. Kuse, K. Yasuda, and M. Shimura, "Photopic negative response in branch retinal vein occlusion with macular edema," International Ophthalmology, vol. 35, no. 1, pp. 19-26, 2015.

[14] C. Hvarfner, S. Andreasson, and J. Larsson, "Multifocal electroretinography and fluorescein angiography in retinal vein occlusion," Retina, vol. 26, no. 3, pp. 292-296, 2006.

[15] N. Suzuki, Y. Hirano, M. Yoshida et al., "Microvascular abnormalities on optical coherence tomography angiography in macular edema associated with branch retinal vein occlusion," American Journal of Ophthalmology, vol. 161, pp. 126-132.e1, 2016.

[16] A. H. L. S. Kashani, A. Moshfeghi, M. K. Durbin, and C. A. Puliafito, "Optical coherence tomography angiography of retinal venous occlusion," Retina, vol. 35 , no. 11 , pp. 2323-2331, 2015.

[17] S. S. Hayreh, "Ocular vascular occlusive disorders: natural history of visual outcome," Progress in Retinal and Eye Research, vol. 41, pp. 1-25, 2014.

[18] F. Coscas, A. Glacet-Bernard, A. Miere et al., "Optical coherence tomography angiography in retinal vein occlusion: evaluation of superficial and deep capillary plexa," American Journal of Ophthalmology, vol. 161, pp. 160-171.e2, 2016.

[19] R. Mastropasqua, L. Di Antonio, S. Di Staso et al., "Optical coherence tomography angiography in retinal vascular diseases and choroidal neovascularization," Journal of Ophthalmology, vol. 2015, Article ID 343515, 8 pages, 2015.
[20] J. S. S. Zhao, R. D. Sperduto, E. Y. Chew, and N. A. Remaley, "Arteriovenous crossing patterns in branch retinal vein occlusion," Ophthalmology, vol. 100, no. 3, pp. 423-428, 1993.

[21] N. L. Christoffersen and M. Larsen, "Pathophysiology and hemodynamic of branch retinal vein occlusion," Ophthalmology, vol. 106, no. 11, pp. 2054-2062, 1999.

[22] G. E. L. G. Trope, B. M. McArdle, J. T. Douglas, C. D. Forbes, C. M. Prentice, and W. S. Foulds, "Abnormal blood viscosity and haemostasis in long-standing retinal vein occlusion," The British Journal of Ophthalmology, vol. 67, no. 3, pp. 137-142, 1983.

[23] H. C. W. J. Chen, A. Gupta, A. Luckie, and E. M. Kohner, "Effect of isovolaemic haemodilution on visual outcome in branch retinal vein occlusion," The British Journal of Ophthalmology, vol. 82, no. 2, pp. 162-167, 1998.

[24] M. C. Janssen, M. den Heijer, J. R. Cruysberg, H. Wollersheim, and S. J. Bredie, "Retinal vein occlusion: a form of venous thrombosis or a complication of atherosclerosis? A metaanalysis of thrombophilic factors," Thrombosis and Haemostasis, vol. 93, no. 6, pp. 1021-1026, 2005.

[25] N. Ueda-Arakawa, A. Tsujikawa, K. Yamashiro, S. Ooto, H. Tamura, and N. Yoshimura, "Visual prognosis of eyes with submacular hemorrhage associated with exudative age-related macular degeneration," Japanese Journal of Ophthalmology, vol. 56, no. 6, pp. 589-598, 2012.

[26] W. Chang, S. J. Garg, R. Maturi et al., "Management of thick submacular hemorrhage with subretinal tissue plasminogen activator and pneumatic displacement for age-related macular degeneration," American Journal of Ophthalmology, vol. 157, no. 6, pp. 1250-1257, 2014.

[27] C. A. Toth, L. S. Morse, L. M. Hjelmeland, and M. B. Landers 3rd, "Fibrin directs early retinal damage after experimental subretinal hemorrhage," Archives of Ophthalmology, vol. 109, no. 5, pp. 723-729, 1991.

[28] E. Dominguez, W. Raoul, B. Calippe et al., "Experimental branch retinal vein occlusion induces upstream pericyte loss and vascular destabilization," PLoS One, vol. 10, no. 7, article e0132644, 2015.

[29] J. Q. Zhou, L. Xu, S. Wang et al., "The 10-year incidence and risk factors of retinal vein occlusion: the Beijing eye study," Ophthalmology, vol. 120, no. 4, pp. 803-808, 2013.

[30] A. Arnarsson and E. Stefánsson, "Laser treatment and the mechanism of edema reduction in branch retinal vein occlusion," Investigative Ophthalmology \& Visual Science, vol. 41, no. 3, pp. 877-879, 2000.

[31] R. M. Silva, J. R. Faria de Abreu, and J. G. Cunha-Vaz, "Blood-retina barrier in acute retinal branch vein occlusion," Graefe's Archive for Clinical and Experimental Ophthalmology, vol. 233, no. 11, pp. 721-726, 1995.

[32] S. T. T. Saika, T. Miyamoto, and Y. Ohnishi, "Surgical posterior vitreous detachment combined with gas/air tamponade for treating macular edema associated with branch retinal vein occlusion: retinal tomography and visual outcome," Graefe's Archive for Clinical and Experimental Ophthalmo$\log$, vol. 239, no. 10, pp. 729-732, 2001.

[33] H. M. A. Noma, H. Funatsu, H. Tsukamoto, K. Nakano, H. Yamashita, and H. K. Mishima, "Intravitreal levels of vascular endothelial growth factor and interleukin-6 are correlated with macular edema in branch retinal vein occlusion," Graefe's Archive for Clinical and Experimental Ophthalmology, vol. 244, no. 3, pp. 309-315, 2006. 
[34] H. Noma, H. Funatsu, M. Yamasaki et al., "Aqueous humour levels of cytokines are correlated to vitreous levels and severity of macular oedema in branch retinal vein occlusion," Eye (London), vol. 22, no. 1, pp. 42-48, 2008.

[35] L. P. Aiello, R. L. Avery, P. G. Arrigg et al., "Vascular endothelial growth factor in ocular fluid of patients with diabetic retinopathy and other retinal disorders," New England Journal of Medicine, vol. 331, no. 22, pp. 1480-1487, 1994.

[36] H. Noma, H. Funatsu, T. Mimura, S. Eguchi, and K. Shimada, "Role of soluble vascular endothelial growth factor receptor-2 in macular oedema with central retinal vein occlusion," The British Journal of Ophthalmology, vol. 95, no. 6, pp. 788-792, 2011.

[37] H. Noma and T. Mimura, "Aqueous soluble vascular endothelial growth factor receptor-2 in macular edema with branch retinal vein occlusion," Current Eye Research, vol. 38, no. 12, pp. 1288-1290, 2013.

[38] H. Noma, T. Mimura, K. Yasuda, and M. Shimura, "Cytokine kinetics after monthly intravitreal bevacizumab for retinal vein occlusion associated with macular oedema," Ophthalmic Research, vol. 56, no. 4, pp. 207-214, 2016.

[39] H. Noma, T. Mimura, and K. Shimada, "Role of inflammation in previously untreated macular edema with branch retinal vein occlusion," BMC Ophthalmology, vol. 14, no. 1, p. 67, 2014.

[40] J. H. S. J. Kim, I. T. Kim, and D. H. Park, "Aqueous angiopoietin-like 4 levels correlate with nonperfusion area and macular edema in branch retinal vein occlusion," Investigative Ophthalmology \& Visual Science, vol. 57, no. 1, pp. 6-11, 2016.

[41] X. Xin, M. Rodrigues, M. Umapathi et al., "Hypoxic retinal Muller cells promote vascular permeability by HIF-1dependent up-regulation of angiopoietin-like 4," Proceedings of the National Academy of Sciences of the United States of America, vol. 110, no. 36, pp. E3425-E3434, 2013.

[42] T. Ma, B. C. Jham, J. Hu et al., "Viral G protein-coupled receptor up-regulates angiopoietin-like 4 promoting angiogenesis and vascular permeability in Kaposi's sarcoma," Proceedings of the National Academy of Sciences of the United States of America, vol. 107, no. 32, pp. 1436314368, 2010.

[43] H. J. Shin, H. C. Kim, and J. W. Moon, "Aqueous levels of erythropoietin in acute retinal vein occlusion with macular edema," International Journal of Ophthalmology, vol. 7, no. 3, pp. 501-506, 2014.

[44] S. Bocker-Meffert, P. Rosenstiel, C. Rohl et al., "Erythropoietin and VEGF promote neural outgrowth from retinal explants in postnatal rats," Investigative Ophthalmology \& Visual Science, vol. 43, no. 6, pp. 2021-2026, 2002.

[45] A. K. Junk, A. Mammis, S. I. Savitz et al., "Erythropoietin administration protects retinal neurons from acute ischemiareperfusion injury," Proceedings of the National Academy of Sciences of the United States of America, vol. 99, no. 16, pp. 10659-10664, 2002.

[46] Y. Inomata, A. Hirata, E. Takahashi, T. Kawaji, M. Fukushima, and H. Tanihara, "Elevated erythropoietin in vitreous with ischemic retinal diseases," Neuroreport, vol. 15, no. 5, pp. 877-879, 2004.

[47] P. Kolar, "Risk factors for central and branch retinal vein occlusion: a meta-analysis of published clinical data," Journal of Ophthalmology, vol. 2014, Article ID 724780, p. 5, 2014.
[48] P. A. O’Mahoney, D. T. Wong, and J. G. Ray, "Retinal vein occlusion and traditional risk factors for atherosclerosis," Archives of Ophthalmology, vol. 126, no. 5, pp. 692-699, 2008.

[49] P. A. Newman-Casey, M. Stem, N. Talwar, D. C. Musch, C. G. Besirli, and J. D. Stein, "Risk factors associated with developing branch retinal vein occlusion among enrollees in a United States managed care plan," Ophthalmology, vol. 121, no. 10, pp. 1939-1948, 2014.

[50] H. D. Lam, J. M. Lahey, J. J. Kearney, R. R. Ng, J. M. Lehmer, and S. C. Tanaka, "Young patients with branch retinal vein occlusion: a review of 60 cases," Retina, vol. 30, no. 9, pp. 1520-1523, 2010.

[51] J. Rehak and M. Rehak, "Branch retinal vein occlusion: pathogenesis, visual prognosis, and treatment modalities," Current Eye Research, vol. 33, no. 2, pp. 111-131, 2008.

[52] H. J. Kwon, E. C. Kang, J. Lee, J. Han, and W. K. Song, "Obstructive sleep apnea in patients with branch retinal vein occlusion: a preliminary study," Korean Journal of Ophthalmology, vol. 30, no. 2, pp. 121-126, 2016.

[53] N. Simmons, A. Joseph, and C. Baumal, "Traumatic branch retinal vein occlusion with retinal neovascularization following inadvertent retrobulbar needle perforation," Ophthalmic Surgery, Lasers and Imaging Retina, vol. 47, no. 2, pp. 191-193, 2016.

[54] S. N. Chen, T. C. Yang, J. T. Lin, and I. B. Lian, "End stage renal disease as a potential risk factor for retinal vein occlusion," Medicine (Baltimore), vol. 94, no. 47, article e1960, 2015.

[55] A. Szigeti, M. Schneider, M. Ecsedy, Z. Z. Nagy, and Z. Recsan, "Association between retinal vein occlusion, axial length and vitreous chamber depth measured by optical low coherence reflectometry," BMC Ophthalmology, vol. 15, 45 pages, 2015.

[56] T. Bertelmann, I. Bertelmann, P. Szurman et al., "Vitreous body and retinal vein occlusion," Der Ophthalmologe: Zeitschrift der Deutschen Ophthalmologischen Gesellschaft, vol. 111, no. 12, pp. 1178-1182, 2014.

[57] C. H. Shih, S. Y. Ou, C. J. Shih, Y. T. Chen, S. M. Ou, and Y. J. Lee, "Bidirectional association between the risk of comorbidities and the diagnosis of retinal vein occlusion in an elderly population: a nationwide population-based study," International Journal of Cardiology, vol. 178, pp. 256-261, 2015.

[58] S. Demir, H. Ortak, I. Benli et al., "Genetic association between arterial stiffness-related gene polymorphisms in BRVO and CRVO patients in a Turkish population," Retina, vol. 35, no. 10, pp. 2043-2051, 2015.

[59] F. A. Gutman and H. Zegarra, "The natural course of temporal retinal branch vein occlusion," Transactions American Academy of Ophthalmology and Otolaryngology, vol. 78, no. 2, pp. OP178-OP192, 1974.

[60] S. S. Hayreh and M. B. Zimmerman, "Branch retinal vein occlusion: natural history of visual outcome," JAMA Ophthalmology, vol. 132, no. 1, pp. 13-22, 2014.

[61] S. S. Hayreh, P. A. Podhajsky, and M. B. Zimmerman, "Natural history of visual outcome in central retinal vein occlusion," Ophthalmology, vol. 118, no. 1, pp. 119.e1133.e2, 2011.

[62] A. H. Neufeld, S. I. Kawai, S. Das et al., "Loss of retinal ganglion cells following retinal ischemia: the role of inducible 
nitric oxide synthase," Experimental Eye Research, vol. 75, no. 5, pp. 521-528, 2002.

[63] P. L. Penfold, M. C. Madigan, M. C. Gillies, and J. M. Provis, "Immunological and aetiological aspects of macular degeneration," Progress in Retinal and Eye Research, vol. 20, no. 3, pp. 385-414, 2001.

[64] R. A. Alshareef, G. Barteselli, Q. You et al., "In vivo evaluation of retinal ganglion cells degeneration in eyes with branch retinal vein occlusion," The British Journal of Ophthalmology, 2016.

[65] H. M. Kang, H. J. Koh, and S. C. Lee, "Visual outcome and prognostic factors after surgery for a secondary epiretinal membrane associated with branch retinal vein occlusion," Graefe's Archive for Clinical and Experimental Ophthalmology, vol. 253, no. 4, pp. 543-550, 2015.

[66] M. B. Parodi and F. Bandello, "Branch retinal vein occlusion: classification and treatment," Ophthalmologica, vol. 223, no. 5, pp. 298-305, 2009.

[67] T. Murakami, F. Okamoto, M. Iida et al., "Relationship between metamorphopsia and foveal microstructure in patients with branch retinal vein occlusion and cystoid macular edema," Graefe's Archive for Clinical and Experimental Ophthalmology, vol. 254, no. 11, pp. 2191-2196, 2016.

[68] H. Noma, H. Funatsu, S. Harino, T. Nagaoka, T. Mimura, and S. Hori, "Influence of macular microcirculation and retinal thickness on visual acuity in patients with branch retinal vein occlusion and macular edema," Japanese Journal of Ophthalmology, vol. 54, no. 5, pp. 430-434, 2010.

[69] A. Pielen, N. Feltgen, C. Isserstedt, J. Callizo, B. Junker, and C. Schmucker, "Efficacy and safety of intravitreal therapy in macular edema due to branch and central retinal vein occlusion: a systematic review," PLoS One, vol. 8, no. 10, article e78538, 2013.

[70] E. J. Chung, Y. T. Hong, S. C. Lee, O. W. Kwon, and H. J. Koh, "Prognostic factors for visual outcome after intravitreal bevacizumab for macular edema due to branch retinal vein occlusion," Graefe's Archive for Clinical and Experimental Ophthalmology, vol. 246, no. 9, pp. 1241-1247, 2008.

[71] J. Rehak, L. Dusek, O. Chrapek, E. Fric, and M. Rehak, "Initial visual acuity is an important prognostic factor in patients with branch retinal vein occlusion," Ophthalmic Research, vol. 45, no. 4, pp. 204-209, 2011.

[72] S. J. Kim, Y. H. Yoon, H. K. Kim et al., "Baseline predictors of visual acuity and retinal thickness in patients with retinal vein occlusion," Journal of Korean Medical Science, vol. 30, no. 4, pp. 475-482, 2015.

[73] F. A. Gutman, "Macular edema in branch retinal vein occlusion: prognosis and management," Transactions American Academy of Ophthalmology and Otolaryngology, vol. 83, no. 3 Pt 1, pp. 488-493, 1977.

[74] S. U. Baek, S. I. Kwon, I. W. Park, and K. J. Choi, "Consecutive macular edema and visual outcome in branch retinal vein occlusion," Journal of Ophthalmology, vol. 2014, Article ID 439483, 6 pages, 2014.

[75] A. M. Avunduk, K. Çetinkaya, Z. Kapiciolu, and C. Kaya, "The effect of posterior vitreous detachment on the prognosis of branch retinal vein occlusion," Acta Ophthalmologica Scandinavica, vol. 75, no. 4, pp. 441-442, 1997.

[76] T. Groneberg, J. S. Trattnig, N. Feucht, C. P. Lohmann, and M. Maier, "Morphologic patterns on spectral-domain optical coherence tomography (SD-OCT) as a prognostic indicator in treatment of macular edema due to retinal vein occlusion," Klinische Monatsblätter für Augenheilkunde, vol. 233, no. 9, pp. 1056-1062, 2016.

[77] A. E. Hoeh, M. Ruppenstein, T. Ach, and S. Dithmar, "OCT patterns of macular edema and response to bevacizumab therapy in retinal vein occlusion," Graefe's Archive for Clinical and Experimental Ophthalmology, vol. 248, no. 11, pp. 1567-1572, 2010.

[78] J. W. Kang, H. Lee, H. Chung, and H. C. Kim, “Correlation between optical coherence tomographic hyperreflective foci and visual outcomes after intravitreal bevacizumab for macular edema in branch retinal vein occlusion," Graefe's Archive for Clinical and Experimental Ophthalmology, vol. 252, no. 9, pp. 1413-1421, 2014.

[79] H. Noma, H. Funatsu, T. Mimura, S. Eguchi, and K. Shimada, "Visual prognosis and vitreous molecules after vitrectomy for macular edema with branch retinal vein occlusion," Clinical Ophthalmology, vol. 5, pp. 223-229, 2011.

[80] M. Sugimoto, A. Ichio, and M. Kondo, "Importance of central retinal sensitivity for prediction of visual acuity after intravitreal bevacizumb in eyes with macular edema associated with branch retinal vein occlusion," PLoS One, vol. 11, no. 2, article e0149246, 2016.

[81] Y. Iesato, A. Imai, T. Hirano, Y. Toriyama, and T. Murata, "Effect of leaking capillaries and microaneurysms in the perifoveal capillary network on resolution of macular edema by anti-vascular endothelial growth factor treatment," Japanese Journal of Ophthalmology, vol. 60, no. 2, pp. 86-94, 2016.

[82] K. Abri Aghdam, L. Reznicek, M. Soltan Sanjari et al., "Peripheral retinal non-perfusion and treatment response in branch retinal vein occlusion," International Journal of Ophthalmology, vol. 9, no. 6, pp. 858-862, 2016.

[83] C. Farinha, J. P. Marques, E. Almeida et al., "Treatment of retinal vein occlusion with ranibizumab in clinical practice: longer-term results and predictive factors of functional outcome," Ophthalmic Research, vol. 55, no. 1, pp. 10-18, 2015.

[84] M. Ota, A. Tsujikawa, T. Murakami et al., "Association between integrity of foveal photoreceptor layer and visual acuity in branch retinal vein occlusion," The British Journal of Ophthalmology, vol. 91, no. 12, pp. 1644-1649, 2007.

[85] H. Ohashi, H. Oh, H. Nishiwaki, A. Nonaka, and H. Takagi, "Delayed absorption of macular edema accompanying serous retinal detachment after grid laser treatment in patients with branch retinal vein occlusion," Ophthalmology, vol. 111, no. 11, pp. 2050-2056, 2004.

[86] L. Zhao, B. Li, K. Feng, L. Han, Z. Ma, and Y. Liu, "Bevacizumab treatment for acute branch retinal vein occlusion accompanied by subretinal hemorrhage," Current Eye Research, vol. 40, no. 7, pp. 752-756, 2015.

[87] M. D. Wang, K. W. Jeng-Miller, H. L. Feng, J. L. Prenner, H. F. Fine, and S. P. Shah, "Retina specialists treating cystoid macular oedema secondary to retinal vein occlusion recommend different treatments for patients than they would choose for themselves," The British Journal of Ophthalmology, vol. 100, no. 10, pp. 1332-1336, 2015.

[88] P. Hahn and S. Fekrat, "Best practices for treatment of retinal vein occlusion," Current Opinion in Ophthalmology, vol. 23, no. 3, pp. 175-181, 2012.

[89] T. Kornhauser, R. Schwartz, M. Goldstein, M. Neudorfer, A. Loewenstein, and A. Barak, "Bevacizumab treatment 
of macular edema in CRVO and BRVO: long-term followup. (BERVOLT study: bevacizumab for RVO long-term follow-up)," Graefe's Archive for Clinical and Experimental Ophthalmology, vol. 254, no. 5, pp. 835-844, 2016.

[90] R. Tadayoni, S. M. Waldstein, F. Boscia et al., "Individualized stabilization criteria-driven ranibizumab versus laser in branch retinal vein occlusion: six-month results of BRIGHTER," Ophthalmology, vol. 123, no. 6, pp. 13321344, 2016.

[91] W. L. Clark, D. S. Boyer, J. S. Heier et al., "Intravitreal aflibercept for macular edema following branch retinal vein occlusion: 52-week results of the VIBRANT study," Ophthalmology, vol. 123, no. 2, pp. 330-336, 2016.

[92] P. A. Campochiaro, G. Hafiz, T. A. Mir et al., "Scatter photocoagulation does not reduce macular edema or treatment burden in patients with retinal vein occlusion: the RELATE trial," Ophthalmology, vol. 122, no. 7, pp. 1426-1437, 2015.

[93] R. Narayanan, B. Panchal, T. Das, J. Chhablani, S. Jalali, and M. H. Ali, "A randomised, double-masked, controlled study of the efficacy and safety of intravitreal bevacizumab versus ranibizumab in the treatment of macular oedema due to branch retinal vein occlusion: MARVEL report no. 1," The British Journal of Ophthalmology, vol. 99, no. 7, pp. 954-959, 2015.

[94] A. Pielen, A. Mirshahi, N. Feltgen et al., "Ranibizumab for branch retinal vein occlusion associated macular edema study (RABAMES): six-month results of a prospective randomized clinical trial," Acta Ophthalmologica, vol. 93, no. 1, pp. e29e37, 2015.

[95] D. M. Brown, P. A. Campochiaro, R. B. Bhisitkul et al., "Sustained benefits from ranibizumab for macular edema following branch retinal vein occlusion: 12-month outcomes of a phase III study," Ophthalmology, vol. 118, no. 8, pp. 1594-1602, 2011.

[96] J. S. Heier, P. A. Campochiaro, L. Yau et al., "Ranibizumab for macular edema due to retinal vein occlusions: long-term follow-up in the HORIZON trial," Ophthalmology, vol. 119, no. 4, pp. 802-809, 2012.

[97] P. A. Campochiaro, R. Sophie, J. Pearlman et al., "Long-term outcomes in patients with retinal vein occlusion treated with ranibizumab: the RETAIN study," Ophthalmology, vol. 121, no. 1, pp. 209-219, 2014.

[98] P. A. Campochiaro, C. C. Wykoff, M. Singer et al., "Monthly versus as-needed ranibizumab injections in patients with retinal vein occlusion: the SHORE study," Ophthalmology, vol. 121, no. 12, pp. 2432-2442, 2014.

[99] L. O. Hattenbach, "Efficacy and safety of $0.5 \mathrm{mg}$ ranibizumab compared with $0.7 \mathrm{mg}$ dexamethasone intravitreal implant in patients with branch retinal vein occlusion over 6 months: the COMRADE-B study," Investigative Ophthalmology \& Visual Science, vol. 55, no. 13, 1830 pages, 2014.

[100] H. Noma, K. Yasuda, T. Minezaki, S. Watarai, and M. Shimura, "Changes of retinal flow volume after intravitreal injection of bevacizumab in branch retinal vein occlusion with macular edema: a case series," BMC Ophthalmology, vol. 16, no. 1, p. 61, 2016.

[101] Y. Sun and Y. Qu, "Comparison of intravitreal bevacizumab with intravitreal triamcinolone acetonide for treatment of cystoid macular edema secondary to retinal vein occlusion: a meta-analysis," International Journal of Ophthalmology, vol. 8, no. 6, pp. 1234-1239, 2015.

[102] T. Hikichi, M. Higuchi, T. Matsushita et al., "Two-year outcomes of intravitreal bevacizumab therapy for macular oedema secondary to branch retinal vein occlusion," The British Journal of Ophthalmology, vol. 98, no. 2, pp. 195199, 2014.

[103] M. B. Parodi, P. Iacono, and F. Bandello, "Subthreshold grid laser versus intravitreal bevacizumab as second-line therapy for macular edema in branch retinal vein occlusion recurring after conventional grid laser treatment," Graefe's Archive for Clinical and Experimental Ophthalmology, vol. 253, no. 10, pp. 1647-1651, 2015.

[104] R. Yamada, A. Nishida, M. Shimozono et al., "Predictive factors for recurrence of macular edema after successful intravitreal bevacizumab therapy in branch retinal vein occlusion," Japanese Journal of Ophthalmology, vol. 59, no. 6, pp. 389-393, 2015.

[105] S. Yasuda, M. Kondo, S. Kachi et al., "Rebound of macular edema after intravitreal bevacizumab therapy in eyes with macular edema secondary to branch retinal vein occlusion," Retina, vol. 31, no. 6, pp. 1075-1082, 2011.

[106] S. Rezar, K. Eibenberger, W. Buhl, M. Georgopoulos, U. Schmidt-Erfurth, and S. Sacu, "Anti-VEGF treatment in branch retinal vein occlusion: a real-world experience over 4 years," Acta Ophthalmologica, vol. 93, no. 8, pp. 719-725, 2015.

[107] P. A. Campochiaro, J. S. Heier, L. Feiner et al., "Ranibizumab for macular edema following branch retinal vein occlusion: six-month primary end point results of a phase III study," Ophthalmology, vol. 117, no. 6, pp. 11021112.e1, 2010.

[108] T. A. Mir, S. Kherani, G. Hafiz et al., "Changes in retinal nonperfusion associated with suppression of vascular endothelial growth factor in retinal vein occlusion," Ophthalmology, vol. 123, no. 3, pp. 625-634.e1, 2016.

[109] Y. Muraoka, A. Tsujikawa, A. Takahashi et al., "Foveal damage due to subfoveal hemorrhage associated with branch retinal vein occlusion," PLoS One, vol. 10, no. 12, article e0144894, 2015.

[110] X. Chen, J. Li, M. Li et al., "KH902 suppresses high glucoseinduced migration and sprouting of human retinal endothelial cells by blocking VEGF and PIGF," Diabetes, Obesity \& Metabolism, vol. 15, no. 3, pp. 224-233, 2013.

[111] A. Shinkai, M. Ito, H. Anazawa, S. Yamaguchi, K. Shitara, and M. Shibuya, "Mapping of the sites involved in ligand association and dissociation at the extracellular domain of the kinase insert domain-containing receptor for vascular endothelial growth factor," The Journal of Biological Chemistry, vol. 273, no. 47, pp. 31283-31288, 1998.

[112] M. Zhang, J. Zhang, M. Yan et al., “A phase 1 study of KH902, a vascular endothelial growth factor receptor decoy, for exudative age-related macular degeneration," Ophthalmology, vol. 118, no. 4, pp. 672-678, 2011.

[113] T. T. Nguyen and R. Guymer, "Conbercept (KH-902) for the treatment of neovascular age-related macular degeneration," Expert Review of Clinical Pharmacology, vol. 8, no. 5, pp. 541-548, 2015.

[114] L. Su, X. Ren, H. Wei et al., "Intravitreal conbercept (KH902) for surgical treatment of severe proliferative diabetic retinopathy," Retina, vol. 36, no. 5, pp. 938-943, 2016.

[115] T. Yilmaz and M. Cordero-Coma, "Use of bevacizumab for macular edema secondary to branch retinal vein occlusion: a systematic review," Graefe's Archive for Clinical and Experimental Ophthalmology, vol. 250, no. 6, pp. 787-793, 2012. 
[116] S. A. Regnier, M. Larsen, V. Bezlyak, and F. Allen, "Comparative efficacy and safety of approved treatments for macular oedema secondary to branch retinal vein occlusion: a network meta-analysis," BMJ Open, vol. 5, no. 6, article e007527, 2015.

[117] E. Unsal, K. Eltutar, P. Sultan, and H. Gungel, "Efficacy and safety of Pro Re Nata regimen without loading dose ranibizumab injections in retinal vein occlusion," Pakistan Journal of Medical Sciences, vol. 31, no. 3, pp. 510-515, 2015.

[118] Y. Ito, Y. Saishin, O. Sawada et al., "Comparison of single injection and three monthly injections of intravitreal bevacizumab for macular edema associated with branch retinal vein occlusion," Clinical Ophthalmology, vol. 9, pp. 175-180, 2015.

[119] Y. Sakanishi, A. Lee, A. Usui-Ouchi, R. Ito, and N. Ebihara, "Twelve-month outcomes in patients with retinal vein occlusion treated with low-frequency intravitreal ranibizumab," Clinical Ophthalmology, vol. 10, pp. 1161-1165, 2016.

[120] R. B. Rush, M. P. Simunovic, A. V. Aragon 2nd, and J. E. Ysasaga, "Treat-and-extend intravitreal bevacizumab for branch retinal vein occlusion," Ophthalmic Surgery, Lasers \& Imaging Retina, vol. 45, no. 3, pp. 212-216, 2014.

[121] M. C. Gillies, "What we don't know about avastin might hurt us," Archives of Ophthalmology, vol. 124, no. 10, pp. 14781479, 2006.

[122] B. Oosthuyse, L. Moons, E. Storkebaum et al., "Deletion of the hypoxia-response element in the vascular endothelial growth factor promoter causes motor neuron degeneration," Nature Genetics, vol. 28, no. 2, pp. 131-138, 2001.

[123] T. W. S, ASRS Preferences and Trends Membership Survey, American Society of Retina Specialists, August 2015, https://www.asrs.org/content/documents/_2015-pat-surveyresults.pdf. 2015.

[124] E. Yumusak, N. Buyuktortop, and K. Ornek, "Early results of dexamethasone implant, ranibizumab, and triamcinolone in macular edema due to branch retinal vein occlusion," European Journal of Ophthalmology, vol. 26, no. 1, pp. 54-59, 2016.

[125] A. Ramezani, H. Esfandiari, M. Entezari et al., "Three intravitreal bevacizumab versus two intravitreal triamcinolone injections in recent-onset branch retinal vein occlusion," Graefe's Archive for Clinical and Experimental Ophthalmology, vol. 250, no. 8, pp. 1149-1160, 2012.

[126] J. T. Thompson, "Cataract formation and other complications of intravitreal triamcinolone for macular edema," American Journal of Ophthalmology, vol. 141, no. 4, pp. 629-637, 2006.

[127] W. Kiddee, G. E. Trope, L. Sheng et al., "Intraocular pressure monitoring post intravitreal steroids: a systematic review," Survey of Ophthalmology, vol. 58, no. 4, pp. 291-310, 2013.

[128] J. B. Jonas, R. Degenring, I. Kreissig, and I. Akkoyun, "Safety of intravitreal high-dose reinjections of triamcinolone acetonide," American Journal of Ophthalmology, vol. 138, no. 6, pp. 1054-1055, 2004.

[129] J. Marticorena, F. Gomez-Ulla, M. R. Romano, and I. Luna, "Repeated pseudoendophthalmitis after combined photodynamic therapy and intravitreal triamcinolone," Graefe's Archive for Clinical and Experimental Ophthalmology, vol. 245, no. 9, pp. 1403-1404, 2007.

[130] M. Demir, E. Oba, D. Guven, Z. Acar, and S. Cinar, "Results of intravitreal triamcinolone acetonide in patients with macular edema secondary to branch retinal vein occlusion,"
International Journal of Clinical Pharmacy, vol. 36, no. 2, pp. 438-442, 2014.

[131] I. U. Scott, M. S. Ip, P. C. VanVeldhuisen et al., “A randomized trial comparing the efficacy and safety of intravitreal triamcinolone with standard care to treat vision loss associated with macular edema secondary to branch retinal vein occlusion: the standard care vs corticosteroid for retinal vein occlusion (SCORE) study report 6," Archives of Ophthalmology, vol. 127, no. 9, pp. 1115-1128, 2009.

[132] I. L. McAllister, S. Vijayasekaran, S. D. Chen, and D. Y. Yu, "Effect of triamcinolone acetonide on vascular endothelial growth factor and occludin levels in branch retinal vein occlusion," American Journal of Ophthalmology, vol. 147, no. 5, pp. 838-846, 2009, 46 e1-2.

[133] S. Zhang, N. An, W. Ha et al., "Factors correlated with the resolution of macular oedema after one dose injection of intravitreal triamcinolone acetonide treatment in branch retinal vein occlusion," The Journal of International Medical Research, vol. 44, no. 3, pp. 685-697, 2016.

[134] A. Ozkiris, C. Evereklioglu, K. Erkilic, and H. Dogan, "Intravitreal triamcinolone acetonide for treatment of persistent macular oedema in branch retinal vein occlusion," Eye (London), vol. 20, no. 1, pp. 13-17, 2006.

[135] H. Noma, H. Funatsu, T. Mimura, and K. Shimada, "Macular sensitivity and morphology after intravitreal injection of triamcinolone acetonide for macular edema with branch retinal vein occlusion," Retina, vol. 32, no. 9, pp. 1844-1852, 2012.

[136] K. Hayashi and H. Hayashi, "Intravitreal versus retrobulbar injections of triamcinolone for macular edema associated with branch retinal vein occlusion," American Journal of Ophthalmology, vol. 139, no. 6, pp. 972-982, 2005.

[137] O. Cekic, S. Chang, J. J. Tseng et al., "Intravitreal triamcinolone injection for treatment of macular edema secondary to branch retinal vein occlusion," Retina, vol. 25, no. 7, pp. 851-855, 2005.

[138] J. Y. Oh, J. H. Seo, J. K. Ahn, J. W. Heo, and H. Chung, "Early versus late intravitreal triamcinolone acetonide for macular edema associated with branch retinal vein occlusion," Korean Journal of Ophthalmology, vol. 21, no. 1, pp. 18-20, 2007.

[139] R. Kawamura, M. Inoue, H. Shinoda et al., "Incidence of increased intraocular pressure after subtenon injection of triamcinolone acetonide," Journal of Ocular Pharmacology and Therapeutics, vol. 27, no. 3, pp. 299-304, 2011.

[140] J. A. Cardillo, L. A. Melo Jr., R. A. Costa et al., "Comparison of intravitreal versus posterior sub-Tenon's capsule injection of triamcinolone acetonide for diffuse diabetic macular edema," Ophthalmology, vol. 112, no. 9, pp. 1557-1563, 2005.

[141] S. Winterhalter, G. A. Vom Brocke, M. K. Klamann, B. Muller, and A. M. Joussen, "Monthly microperimetry (MP1) measurement of macular sensitivity after dexamethasone implantation (Ozurdex) in retinal vein occlusions," Graefe's Archive for Clinical and Experimental Ophthalmology, vol. 253, no. 11, pp. 1873-1882, 2015.

[142] S. J. Sheu, T. T. Wu, and Y. H. Horng, "Efficacy and safety of dexamethasone intravitreal implant for treatment of refractory macular edema secondary to retinal vein occlusion in Taiwan," Journal of Ocular Pharmacology and Therapeutics, vol. 31, no. 8, pp. 461-467, 2015.

[143] W. J. Mayer, A. Hadjigoli, A. Wolf, T. Herold, and C. Haritoglou, "Comparison of intravitreal dexamethasone implant versus intravitreal ranibizumab as a first-line 
treatment of macular oedema due to retinal vein occlusion," Klinische Monatsblätter für Augenheilkunde, vol. 232, no. 11, pp. 1289-1296, 2015.

[144] M. Kola, D. Hacioglu, A. Turk, and H. Erdol, "The effectiveness and reliability of posterior sub-Tenon triamcinolone acetonide injection in branch retinal vein occlusion-related macular edema," Cutaneous and Ocular Toxicology, vol. 35, no. 3, pp. 185-189, 2016.

[145] M. Kim, D. H. Lee, S. H. Byeon, H. J. Koh, S. S. Kim, and S. C. Lee, "Comparison of intravitreal bevacizumab and dexamethasone implant for the treatment of macula oedema associated with branch retinal vein occlusion," The British Journal of Ophthalmology, vol. 99, no. 9, pp. 1271-1276, 2015.

[146] J. A. Haller, F. Bandello, R. Belfort Jr et al.M. S. Blumenkranz, M. Gillies, J. Heier et al., "Dexamethasone intravitreal implant in patients with macular edema related to branch or central retinal vein occlusion twelve-month study results," Ophthalmology, vol. 118, no. 12, pp. 2453-2460, 2011.

[147] J. A. Haller, F. Bandello, R. Belfort Jr et al.M. S. Blumenkranz, M. Gillies, J. Heier et al., "Randomized, sham-controlled trial of dexamethasone intravitreal implant in patients with macular edema due to retinal vein occlusion," Ophthalmology, vol. 117, no. 6, pp. 1134-1146.e3, 2010.

[148] P. A. Campochiaro, G. Hafiz, T. A. Mir et al., "Pro-permeability factors after dexamethasone implant in retinal vein occlusion; the Ozurdex for retinal vein occlusion (ORVO) study," American Journal of Ophthalmology, vol. 160, no. 2, pp. 313321.e19, 2015.

[149] S. Rezar-Dreindl, K. Eibenberger, A. Pollreisz et al., "Effect of intravitreal dexamethasone implant on intra-ocular cytokines and chemokines in eyes with retinal vein occlusion," Acta Ophthalmologica, vol. 95, no. 2, pp. e119-e127, 2017.

[150] A. Capone Jr., M. A. Singer, D. G. Dodwell et al., "Efficacy and safety of two or more dexamethasone intravitreal implant injections for treatment of macular edema related to retinal vein occlusion (Shasta study)," Retina, vol. 34, no. 2, pp. 342-351, 2014.

[151] A. Ozkok, O. A. Saleh, D. K. Sigford, J. W. Heroman, and S. Schaal, "The OMAR study: comparison of Ozurdex and triamcinolone acetonide for refractory cystoid macular edema in retinal vein occlusion," Retina, vol. 35, no. 7, pp. 13931400, 2015.

[152] A. Bezatis, G. Spital, F. Hohn et al., "Functional and anatomical results after a single intravitreal Ozurdex injection in retinal vein occlusion: a 6-month follow-up - the SOLO study," Acta Ophthalmologica, vol. 91, no. 5, pp. e340-e347, 2013.

[153] R. Sophie, G. Hafiz, A. W. Scott et al., "Long-term outcomes in ranibizumab-treated patients with retinal vein occlusion; the role of progression of retinal nonperfusion," American Journal of Ophthalmology, vol. 156, no. 4, pp. 693-705, 2013.

[154] P. A. Campochiaro, R. B. Bhisitkul, H. Shapiro, and R. G. Rubio, "Vascular endothelial growth factor promotes progressive retinal nonperfusion in patients with retinal vein occlusion," Ophthalmology, vol. 120, no. 4, pp. 795-802, 2013.

[155] The Branch Vein Occlusion Study G, "Argon laser photocoagulation for macular edema in branch vein occlusion," American Journal of Ophthalmology, vol. 98, no. 3, pp. 271282, 1984.

[156] N. Ogata, J. Tombran-Tink, N. Jo, D. Mrazek, and M. Matsumura, "Upregulation of pigment epithelium- derived factor after laser photocoagulation," American Journal of Ophthalmology, vol. 132, no. 3, pp. 427429, 2001.

[157] L. O. Hattenbach, K. F. Beck, J. Pfeilschifter, F. Koch, C. Ohrloff, and W. Schacke, "Pigment-epithelium-derived factor is upregulated in photocoagulated human retinal pigment epithelial cells," Ophthalmic Research, vol. 37, no. 6, pp. 341-346, 2005.

[158] K. Mori, E. Duh, P. Gehlbach et al., "Pigment epitheliumderived factor inhibits retinal and choroidal neovascularization," Journal of Cellular Physiology, vol. 188, no. 2, pp. 253-263, 2001.

[159] E. Konac, K. Sonmez, M. Bahcelioglu et al., "Does pattern scan laser (PASCAL) photocoagulation really induce less VEGF expression in murine retina than conventional laser treatment?" Gene, vol. 549, no. 1, pp. 156-160, 2014.

[160] S. Sakimoto, M. Kamei, H. Sakaguchi et al., "Direct photocoagulation to leakage points to treat chronic macular edema associated with branch retinal vein occlusion: a pilot study," Clinical Ophthalmology, vol. 8, pp. 2055-2060, 2014.

[161] H. Schatz, D. Madeira, H. R. McDonald, and R. N. Johnson, "Progressive enlargement of laser scars following grid laser photocoagulation for diffuse diabetic macular edema," Archives of Ophthalmology, vol. 109, no. 11, pp. 1549-1551, 1991.

[162] C. Hudson, J. G. Flanagan, G. S. Turner, H. C. Chen, L. B. Young, and D. McLeod, "Correlation of a scanning laser derived oedema index and visual function following grid laser treatment for diabetic macular oedema," The British Journal of Ophthalmology, vol. 87, no. 4, pp. 455-461, 2003.

[163] D. R. Guyer, D. J. D'Amico, and C. W. Smith, "Subretinal fibrosis after laser photocoagulation for diabetic macular edema," American Journal of Ophthalmology, vol. 113, no. 6, pp. 652-656, 1992.

[164] H. Lewis, A. P. Schachat, M. H. Haimann et al., "Choroidal neovascularization after laser photocoagulation for diabetic macular edema," Ophthalmology, vol. 97, no. 4, pp. 503510, 1990, discussion 10-1.

[165] J. Roider, "Laser treatment of retinal diseases by subthreshold laser effects," Seminars in Ophthalmology, vol. 14, no. 1, pp. 19-26, 1999.

[166] K. Inagaki, K. Ohkoshi, S. Ohde, G. A. Deshpande, N. Ebihara, and A. Murakami, "Subthreshold micropulse photocoagulation for persistent macular edema secondary to branch retinal vein occlusion including best-corrected visual acuity greater than 20/40," Journal of Ophthalmology, vol. 2014, Article ID 251257, 10 pages, 2014.

[167] K. Inagaki, K. Ohkoshi, and S. Ohde, "Spectral-domain optical coherence tomography imaging of retinal changes after conventional multicolor laser, subthreshold micropulse diode laser, or pattern scanning laser therapy in Japanese with macular edema," Retina, vol. 32, no. 8, pp. 1592-1600, 2012.

[168] M. B. Parodi, S. Spasse, P. Iacono, G. Di Stefano, T. Canziani, and G. Ravalico, "Subthreshold grid laser treatment of macular edema secondary to branch retinal vein occlusion with micropulse infrared (810 nanometer) diode laser," Ophthalmology, vol. 113, no. 12, pp. 2237-2242, 2006.

[169] J. Glanville, J. Patterson, R. McCool, A. Ferreira, K. Gairy, and I. Pearce, "Efficacy and safety of widely used treatments for macular oedema secondary to retinal vein 
occlusion: a systematic review," BMC Ophthalmology, vol. 14, p. 7, 2014.

[170] K. Lee, H. Jung, and J. Sohn, "Comparison of injection of intravitreal drugs with standard care in macular edema secondary to branch retinal vein occlusion," Korean Journal of Ophthalmology, vol. 28, no. 1, pp. 19-25, 2014.

[171] J. Rehak, L. Dusek, M. Sin, B. Babkova, Z. Pracharova, and M. Rehak, "Long term visual outcome after arteriolar constriction in patients with branch retinal vein occlusion," Biomedical Papers of the Medical Faculty of the University Palacky, Olomouc, Czech Republic, vol. 158, no. 4, pp. 577-582, 2014.

[172] H. Erdol and N. Akyol, "Arterial crimping in branch retinal vein occlusion with macular edema," Acta Ophthalmologica Scandinavica, vol. 78, no. 4, pp. 456-459, 2000.

[173] P. Koferl, M. Hollborn, J. Rehak et al., "Effects of arteriolar constriction on retinal gene expression and Muller cell responses in a rat model of branch retinal vein occlusion," Graefe's Archive for Clinical and Experimental Ophthalmology, vol. 252, no. 2, pp. 257-265, 2014.

[174] M. D. Osterloh and S. Charles, "Surgical decompression of branch retinal vein occlusions," Archives of Ophthalmology, vol. 106, no. 10, pp. 1469-1471, 1988.

[175] M. Shimura, T. Nakazawa, K. Yasuda, H. Kunikata, T. Shiono, and K. Nishida, "Visual prognosis and vitreous cytokine levels after arteriovenous sheathotomy in branch retinal vein occlusion associated with macular oedema," Acta Ophthalmologica, vol. 86, no. 4, pp. 377-384, 2008.

[176] I. K. Oh, S. Kim, J. Oh, and K. Huh, "Long-term visual outcome of arteriovenous adventitial sheathotomy on branch retinal vein occlusion induced macular edema," Korean Journal of Ophthalmology, vol. 22, no. 1, pp. 1-5, 2008.

[177] J. Mason 3rd, R. Feist, M. White Jr., J. Swanner, G. McGwin Jr., and T. Emond, "Sheathotomy to decompress branch retinal vein occlusion: a matched control study," Ophthalmology, vol. 111, no. 3, pp. 540-545, 2004.

[178] H. Yamaji, F. Shiraga, Y. Tsuchida, Y. Yamamoto, and H. Ohtsuki, "Evaluation of arteriovenous crossing sheathotomy for branch retinal vein occlusion by fluorescein videoangiography and image analysis," American Journal of Ophthalmology, vol. 137, no. 5, pp. 834-841, 2004.

[179] K. Kumagai, M. Furukawa, N. Ogino, A. Uemura, and E. Larson, "Long-term outcomes of vitrectomy with or without arteriovenous sheathotomy in branch retinal vein occlusion," Retina, vol. 27, no. 1, pp. 49-54, 2007.

[180] S. Yamane, M. Kamei, S. Sakimoto et al., "Matched control study of visual outcomes after arteriovenous sheathotomy for branch retinal vein occlusion," Clinical Ophthalmology, vol. 8, pp. 471-476, 2014.

[181] M. M. Muqit, S. Saidkasimova, D. Keating, and J. R. Murdoch, "Long-term study of vascular perfusion effects following arteriovenous sheathotomy for branch retinal vein occlusion," Acta Ophthalmologica, vol. 88, no. 3, pp. e57-e65, 2010.

[182] J. Charbonnel, A. Glacet-Bernard, J. F. Korobelnik et al., "Management of branch retinal vein occlusion with vitrectomy and arteriovenous adventitial sheathotomy, the possible role of surgical posterior vitreous detachment," Graefe's Archive for Clinical and Experimental Ophthalmology, vol. 242, no. 3, pp. 223-228, 2004.

[183] S. Yamamoto, W. Saito, F. Yagi, S. Takeuchi, E. Sato, and S. Mizunoya, "Vitrectomy with or without arteriovenous adventitial sheathotomy for macular edema associated with branch retinal vein occlusion," American Journal of Ophthalmology, vol. 138, no. 6, pp. 907-914, 2004.

[184] S. Sato, M. Inoue, S. Yamane, A. Arakawa, M. Mori, and K. Kadonosono, "Outcomes of microincision vitrectomy surgery with internal limiting membrane peeling for macular edema secondary to branch retinal vein occlusion," Clinical Ophthalmology, vol. 9, pp. 439-444, 2015.

[185] M. Arai, S. Yamamoto, Y. Mitamura, E. Sato, T. Sugawara, and S. Mizunoya, "Efficacy of vitrectomy and internal limiting membrane removal for macular edema associated with branch retinal vein occlusion," Ophthalmologica, vol. 223, no. 3, pp. 172-176, 2009.

[186] E. Stefansson, R. L. Novack, and D. L. Hatchell, "Vitrectomy prevents retinal hypoxia in branch retinal vein occlusion," Investigative Ophthalmology \& Visual Science, vol. 31, no. 2, pp. 284-289, 1990.

[187] L. J. Shen, Y. Q. Chen, D. Cheng et al., "In vivo retinal vein bypass surgery in a porcine model," Current Eye Research, vol. 41, no. 1, pp. 79-87, 2016.

[188] J. H. Sohn and S. J. Song, "Arteriovenous sheathotomy for persistent macular edema in branch retinal vein occlusion," Korean Journal of Ophthalmology, vol. 20, no. 4, pp. 210214, 2006.

[189] T. Yamamoto, M. Kamei, N. Yokoi, T. Yasuhara, M. Tei, and S. Kinoshita, "Comparative effect of antiplatelet therapy in retinal vein occlusion evaluated by the particle-counting method using light scattering," American Journal of Ophthalmology, vol. 138, no. 5, pp. 809-817, 2004.

[190] A. J. Houtsmuller, J. A. Vermeulen, M. Klompe et al., "The influence of ticlopidine on the natural course of retinal vein occlusion," Agents and Actions Supplements, vol. 15, pp. 219-229, 1984.

[191] A. Glacet-Bernard, G. Coscas, A. Chabanel, A. Zourdani, F. Lelong, and M. M. Samama, "A randomized, doublemasked study on the treatment of retinal vein occlusion with troxerutin," American Journal of Ophthalmology, vol. 118, no. 4, pp. 421-429, 1994.

[192] T. Murakami, H. Takagi, M. Kita et al., "Intravitreal tissue plasminogen activator to treat macular edema associated with branch retinal vein occlusion," American Journal of Ophthalmology, vol. 142, no. 2, pp. 318-320, 2006.

[193] G. W. Steinkamp, L. O. Hattenbach, I. Scharrer, and C. Ohrloff, "Front-loading rt PA thrombolytic therapy in central or venous branch occlusions of the retina," Der Ophthalmologe: Zeitschrift der Deutschen Ophthalmologischen Gesellschaft, vol. 91, no. 3, pp. 280-282, 1994.

[194] L. O. Hattenbach, G. Steinkamp, I. Scharrer, and C. Ohrloff, "Fibrinolytic therapy with low-dose recombinant tissue plasminogen activator in retinal vein occlusion," Ophthalmologica, vol. 212, no. 6, pp. 394-398, 1998.

[195] M. Tagami, S. Kusuhara, H. Imai, S. Honda, Y. Tsukahara, and A. Negi, "Impact of intravitreal injection of tissue plasminogen activator on full-field electroretinogram in patients with macular oedema secondary to retinal vein occlusion," Ophthalmologica, vol. 226, no. 2, pp. 81-86, 2011.

[196] K. Kumagai, N. Ogino, M. Furukawa, and E. Larson, “Three treatments for macular edema because of branch retinal vein occlusion: intravitreous bevacizumab or tissue plasminogen activator, and vitrectomy," Retina, vol. 32 , no. 3 , pp. 520 $529,2012$. 
[197] A. Lazo-Langner, J. Hawel, W. Ageno, and M. J. Kovacs, "Low molecular weight heparin for the treatment of retinal vein occlusion: a systematic review and meta-analysis of randomized trials," Haematologica, vol. 95, no. 9, pp. 1587-1593, 2010.

[198] W. Ageno, R. Cattaneo, E. Manfredi et al., "Parnaparin versus aspirin in the treatment of retinal vein occlusion. A randomized, double blind, controlled study," Thrombosis Research, vol. 125, no. 2, pp. 137-141, 2010.

[199] A. G. B. Seth, U. Raina, A. Gupta, and S. Arora, "Intravitreal diclofenac in the treatment of macular edema due to branch retinal vein occlusion," Ophthalmic Surgery, Lasers \& Imaging Retina, vol. 47, no. 2, pp. 149-155, 2016.

[200] C. P. Ring, T. C. Pearson, M. D. Sanders, and G. WetherleyMein, "Viscosity and retinal vein thrombosis," British Journal of Ophthalmology, vol. 60, no. 6, pp. 397-410, 1976.

[201] N. Ashton, "Pathophysiology of retinal cotton-wool spots," British Medical Bulletin, vol. 26, no. 2, pp. 143-150, 1970.

[202] J. R. Murphy, "The influence of $\mathrm{pH}$ and temperature on some physical properties of normal erythrocytes and erythrocytes from patients with hereditary spherecytosis," The Journal of Laboratory and Clinical Medicine, vol. 69, no. 5, pp. 758-775, 1967.

[203] D. J. Thomas, "Whole blood viscosity and cerebral blood flow," Stroke, vol. 13, no. 3, pp. 285-287, 1982.

[204] A. Chabanel, A. Glacet-Bernard, F. Lelong, A. Taccoen, G. Coscas, and M. M. Samama, "Increased red blood cell aggregation in retinal vein occlusion," British Journal of Haematology, vol. 75, no. 1, pp. 127-131, 1990.

[205] J. B. Gunther and M. M. Altaweel, "Bevacizumab (Avastin) for the treatment of ocular disease," Survey of Ophthalmology, vol. 54, no. 3, pp. 372-400, 2009.

[206] W. E. Smiddy, "Economic considerations of macular edema therapies," Ophthalmology, vol. 118, no. 9, pp. 18271833, 2011.

[207] Y. Tomomatsu, T. Tomomatsu, Y. Takamura et al., "Comparative study of combined bevacizumab/targeted photocoagulation vs bevacizumab alone for macular oedema in ischaemic branch retinal vein occlusions," Acta Ophthalmologica, vol. 94, no. 3, pp. e225-e230, 2016.

[208] C. S. Yang, J. H. Liu, Y. C. Chung, Y. B. Chou, and K. H. Hung, "Combination therapy with intravitreal bevacizumab and macular grid and scatter laser photocoagulation in patients with macular edema secondary to branch retinal vein occlusion," Journal of Ocular Pharmacology and Therapeutics, vol. 31, no. 3, pp. 179-185, 2015.

[209] S. Donati, P. Barosi, M. Bianchi, M. Al Oum, and C. Azzolini, "Combined intravitreal bevacizumab and grid laser photocoagulation for macular edema secondary to branch retinal vein occlusion," European Journal of Ophthalmology, vol. 22, no. 4, pp. 607-614, 2012.

[210] M. Shimura and K. Yasuda, "Topical bromfenac reduces the frequency of intravitreal bevacizumab in patients with branch retinal vein occlusion," The British Journal of Ophthalmology, vol. 99, no. 2, pp. 215-219, 2015.

[211] J. Ma, K. Yao, Z. Zhang, and X. Tang, "25-gauge vitrectomy and triamcinolone acetonide-assisted internal limiting membrane peeling for chronic cystoid macular edema associated with branch retinal vein occlusion," Retina, vol. 28, no. 7, pp. 947-956, 2008.
[212] F. Pichi, C. Specchia, L. Vitale et al., "Combination therapy with dexamethasone intravitreal implant and macular grid laser in patients with branch retinal vein occlusion," American Journal of Ophthalmology, vol. 157, no. 3, pp. 607615.e1, 2014.

[213] J. C. Hwang, S. K. Gelman, H. F. Fine, S. Chang, and L. V. Del Priore, "Combined arteriovenous sheathotomy and intraoperative intravitreal triamcinolone acetonide for branch retinal vein occlusion," The British Journal of Ophthalmology, vol. 94, no. 11, pp. 1483-1489, 2010.

[214] J. Riese, V. Loukopoulos, C. Meier, M. Timmermann, and H. Gerding, "Combined intravitreal triamcinolone injection and laser photocoagulation in eyes with persistent macular edema after branch retinal vein occlusion," Graefe's Archive for Clinical and Experimental Ophthalmology, vol. 246, no. 12, pp. 1671-1676, 2008.

[215] S. V. Azad, A. Salman, D. Mahajan, S. Sain, and R. Azad, "Comparative evaluation between ranibizumab combined with laser and bevacizumab combined with laser versus laser alone for macular oedema secondary to branch retinal vein occlusion," Middle East African Journal of Ophthalmology, vol. 21, no. 4, pp. 296-301, 2014.

[216] A. Ozkaya, U. Celik, Z. Alkin, M. Faiz Turan, A. T. Yazici, and A. Demirok, "Comparison between intravitreal triamcinolone with grid laser photocoagulation versus bevacizumab with grid laser photocoagulation combinations for branch retinal vein occlusion," ISRN Ophthalmology, vol. 2013, Article ID 141279, 8 pages, 2013.

[217] R. I. Ali, K. G. Kapoor, A. N. Khan, and S. K. Gibran, "Efficacy of combined intravitreal bevacizumab and triamcinolone for branch retinal vein occlusion," Indian Journal of Ophthalmology, vol. 62, no. 4, pp. 396-399, 2014.

[218] M. B. Parodi, P. Iacono, and G. Ravalico, "Intravitreal triamcinolone acetonide combined with subthreshold grid laser treatment for macular oedema in branch retinal vein occlusion: a pilot study," The British Journal of Ophthalmology, vol. 92, no. 8, pp. 1046-1050, 2008.

[219] A. Tsujikawa, M. Fujihara, T. Iwawaki, K. Yamamoto, and Y. Kurimoto, "Triamcinolone acetonide with vitrectomy for treatment of macular edema associated with branch retinal vein occlusion," Retina, vol. 25, no. 7, pp. 861-867, 2005. 


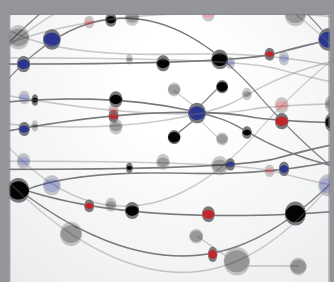

The Scientific World Journal
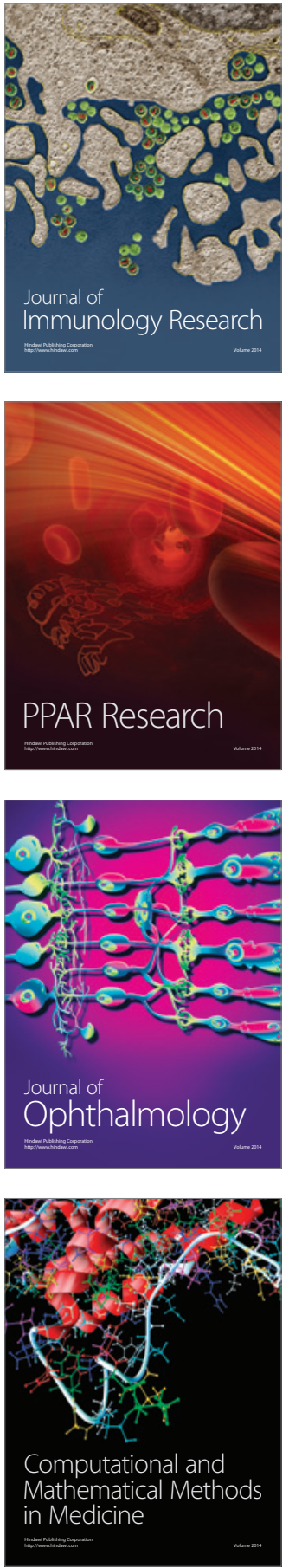

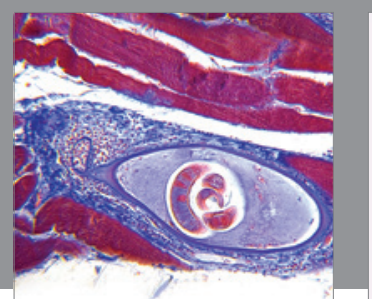

Gastroenterology Research and Practice
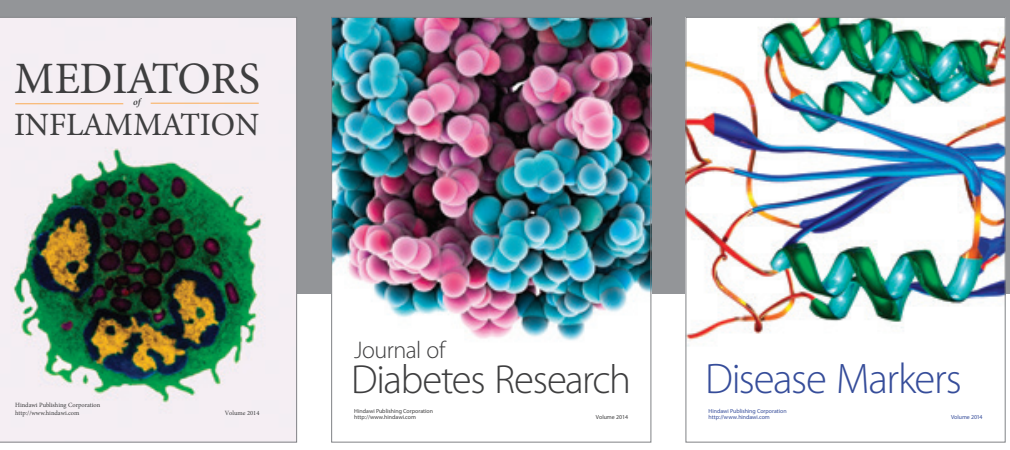

Disease Markers

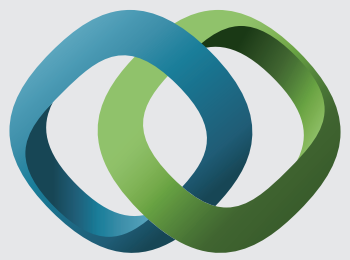

\section{Hindawi}

Submit your manuscripts at

https://www.hindawi.com
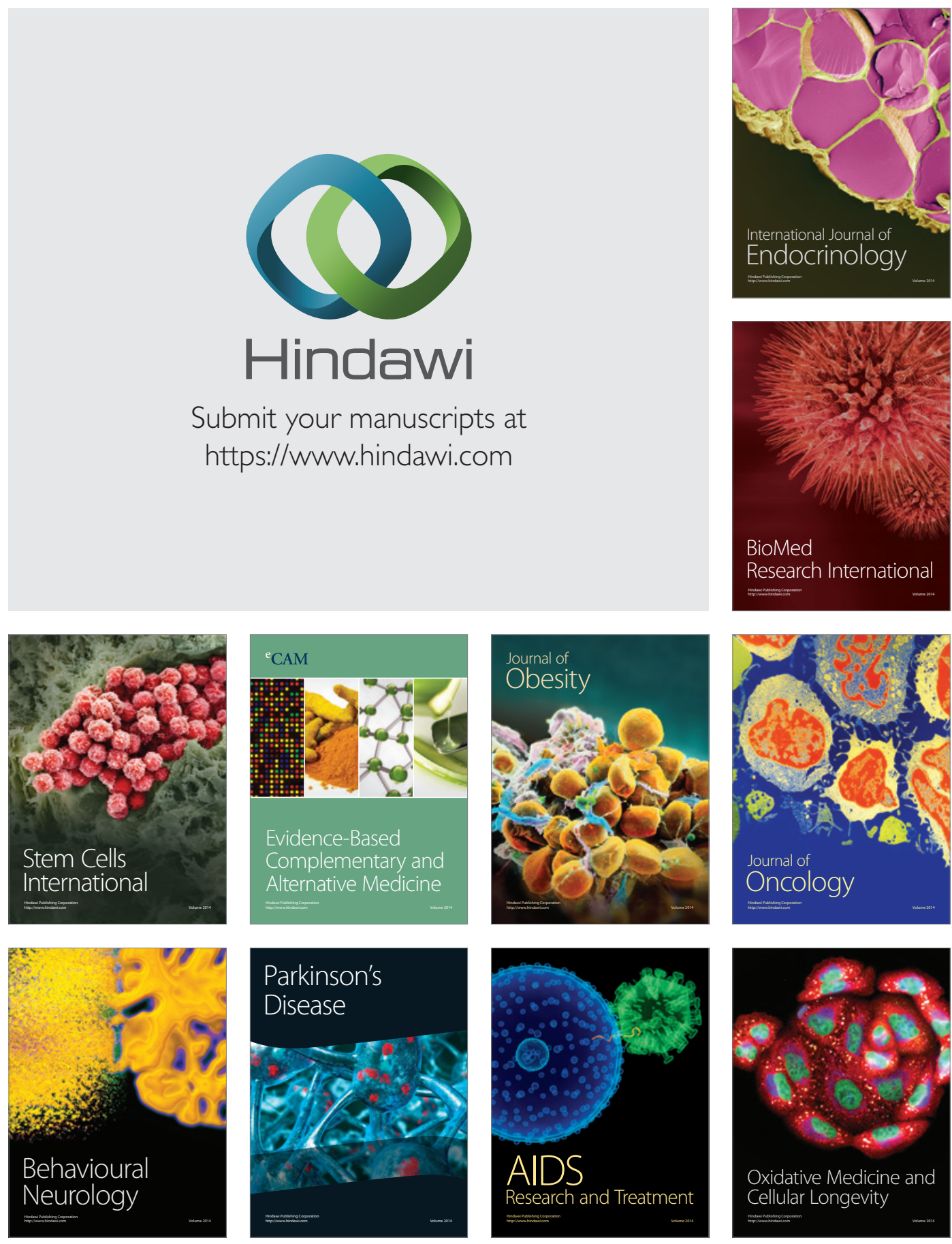